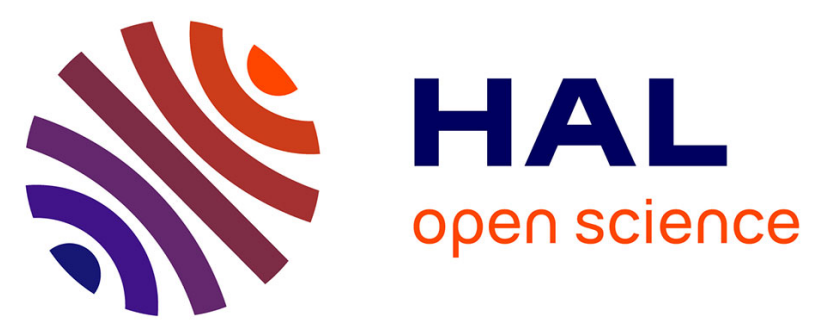

\title{
The Application of Variable Chlorophyll Fluorescence to Microphytobenthic Biofilms
}

Rupert G. Perkins, Jacco C. Kromkamp, Joao Serôdio, Johann Lavaud, Bruno Jesus, Jean-Luc Mouget, Sébastien Lefebvre, R. M. Forster

\section{- To cite this version:}

Rupert G. Perkins, Jacco C. Kromkamp, Joao Serôdio, Johann Lavaud, Bruno Jesus, et al.. The Application of Variable Chlorophyll Fluorescence to Microphytobenthic Biofilms. Chlorophyll a Fluorescence in Aquatic Sciences: Methods and Applications, , 2010, 10.1007/978-90-481-9268-7_12 . hal-01097870

\section{HAL Id: hal-01097870 \\ https://hal.science/hal-01097870}

Submitted on 9 Jan 2015

HAL is a multi-disciplinary open access archive for the deposit and dissemination of scientific research documents, whether they are published or not. The documents may come from teaching and research institutions in France or abroad, or from public or private research centers.
L'archive ouverte pluridisciplinaire HAL, est destinée au dépôt et à la diffusion de documents scientifiques de niveau recherche, publiés ou non, émanant des établissements d'enseignement et de recherche français ou étrangers, des laboratoires publics ou privés. 


\section{The application of variable chlorophyll fluorescence to microphytobenthic biofilms}

Perkins, R.G. ${ }^{{ }^{*}}$, Kromkamp. J. ${ }^{2}$, Serôdio, J. ${ }^{3}$, Lavaud, J. ${ }^{4}$, Jesus, B. ${ }^{5}$, Mouget, J-L. ${ }^{6}$, , Lefebvre, S. ${ }^{7}$, Forster, R. ${ }^{8}$

1. School of Earth and Ocean Sciences, Cardiff University, Main Building, Park Place, Cardiff, CF10 3 YE, UK.

2. NIOO-KNAW Centre for Estuarine and Marine Ecology, P.O. Box 140, 4400 AC Yerseke, The Netherlands

3. Departamento de Biologia, Universidade de Aveiro, Campus de Santiago, 3810-193 Aveiro, Portugal

4. Université de La Rochelle, Technoforum, 23 avenue Albert Einstein, 17071 LA, OCHELLE cedex 9, France

5. Centro de Oceanografia, Faculdade de Ciências da Universidade de Lisboa, Campo grande, 1749-016 Lisboa, Portugal.

6. Laboratoire de Physiologie et de Biochimie végétales, MMS EA 2160, Université du Maine, Av. O. Messiaen, 72085 Le Mans Cedex 9, France

7. Laboratoire de Biologie et Biotechnologies Marine, Université de Caen, Esplanade de la Paix, 14032 Caen cedex, France

8. Ecosystem Interactions, Centre for Environment, Fisheries and Aquaculture Science (CEFAS), Pakefield Road, Lowestoft, Suffolk NR33 OHT, UK 
*corresponding author: Email: PerkinsR@cf.ac.uk; Tel.: 0044 (0)2920 875026. Fax.:

$0044(0) 2920875426$ 


\section{Abstract}

The successful application of variable chlorophyll fluorescence methodology to higher plants and other phototrophs inspired workers in the 1990s to apply the methods to microalgal communities inhabiting benthic soft sediments, the microphytobenthos (MPB) of estuarine and other coastal habitats. It was quickly identified that particular aspects of the physiology (cellular vertical migration within the sediment matrix), photophysiology (high capacity for down regulation, e.g. NPQ, and chlororespiration in the dark) and the effects of the physical structure of the sediment/biofilm matrix (light attenuation by the matrix itself) confounded the interpretation of fluorescence information obtained. In this chapter, the authors attempt to explain these and other issues pertinent to MPB biofilms and to summarise how methods have been developed to alleviate the problems encountered. Although much work is still needed to fully understand fluorescence data for the MPB, studies to date have been highly illuminating with regard to rhythms of productivity, photoacclimatory mechanisms and the behavioural ecology and physiology of MPB at an integrated biofilm level and at a cellular level. This chapter therefore introduces benthic biofilms and relevant specific fluorescence methodological issues, expands on subsurface fluorescence signal and migration, discusses down regulatory nonphotochemical quenching (NPQ) resulting from xanthophylls cycle induction, compares measurement of electron transport rate proxies, examines light curve methodology, and concludes by comparing fluorescence productivity measurements with those of other methodologies such as oxygen evolution and carbon uptake. 


\section{Contents}

1. Introduction to benthic biofilms

2. The effects of subsurface signal

2.1 Microphytobenthic biofilms on soft sediments

2.2 Stromatolites - the effect of "layered" biofilms

2.3 Deconvolution of depth integrated signals

3. Down regulation through Non Photochemical Quenching

3.1 NPQ and the Xanthophyll cycle in diatoms

3.2 NPQ in the dark

4. The quantification of the microalgal biomass using fluorescence

5. Calculation of electron transport rate: ETR v rETR

5.1 Multiple and single turnover methods

5.2 The MT-method.

5.3 The ST-method

5.4 Assumptions and uncertainties.

5.5 Calculation of ETR in microphytobenthos studies

6. Light response curves

6.1 A brief overview of methodology

6.2 Steady sate light curves

6.3 Rapid Light Curves

6.4 Non-sequential Light Curves

6.5 Light Curves Summary

7. Comparison of fluorescence with other methodologies

8. General summary

9. References 


\section{Introduction to benthic biofilms}

Community assemblages of diatoms, green algae and cyanobacteria comprise the microphytobenthos (MPB) inhabiting benthic sediment ecosystems (Admiraal 1984, Underwood and Kromkamp 1999, Consalvey et al. 2004). Particular attention has been paid top the analysis of intertidal soft sediment systems, e.g. cohesive mudflat and sandy substrata typical of estuarine habitats. Variable chlorophyll fluorescence has been applied to these systems since the 1990s, in an attempt to investigate the primary productivity and photophysiology of the integrated biofilms, when viewed as a "black box system", and also the species level (Sections 5, 6 and 7). These transient biofilms are not confined to such soft sediment habitats however, and more recently application of fluorescence methodologies has been applied to biofilms inhabiting rocky shores and stromatolite systems (Kromkamp et al. 2007; Perkins et al. 2007). However the large majority of published work has centred upon benthic softsediment biofilms, due to their important ecosystem functions of carbon flow and sediment stability (Underwood and Kromkamp, 1999). In the former their high magnitude of productivity fuels carbon flow through invertebrate and bacterial food webs to support important trophic levels of anthropogenically exploited taxa, including coastal fish and shell fisheries and coastal avifauna. In the case of sediment stability, biogenic exopolymers, usually referred to as extracellular polymeric substances (EPS), produced by the MPB may contribute significantly to sediment stability, hence increasing the sediment resistance to hydrodynamic stresses and thus resistance to coastal erosion (e.g. Underwood and Kromkamp 1999 and citations there-in). 
One attribute of MPB physiology has in particular contributed to confounding the application of fluorescence methodology to benthic biofilms. This is the behavioural adaptation of the MPB to migrate vertically in their sediment matrix habitat in response to environmental stimuli, as well as part of endogenous tidal and diel rhythms (Sections 2, 3, 4, 5 and 6). Consalvey et al. (2004) reviewed this migration in MPB biofilms and Consalvey et al. (2005) discussed the effect of this as part of a review of fluorescence methodology applied to MPB biofilms. Vertical migration appears to follow tidal and diel rhythms such that cells migrate to the surface of the sediment to coincide with daylight emersion periods, whilst migrating back in to the sediment for immersion periods (Consalvey et al. 2004 and citations there-in). In some instances this appears to be modulated by light environment such that low turbidity in the overlaying water column enables the MPB to remain at the sediment surface after the onset of immersion, and during bright moonlit emersion periods, MPB will migrate to the surface (authors pers. obs.).

Light is undoubtedly a major stimulus in MPB vertical migration. Several studies have shown that cells within MPB biofilms show negative or positive phototaxis. For example, cells will migrate down to avoid potentially harmful high light environments and migrate up to optimise the light environment when ambient light levels are low (Sections 2, 3 and 6). Cells also show "microcycling" such that their can be a constant turnover of taxa at the sediment surface, such that cells shade each other resulting in a reduction in photodose integrated over time (Section 2, 5, 6 and 7). As well as affecting productivity, such "behavioural" down regulation of photosynthesis may act to make interpretation of fluorescence measurements difficult. For example, cells will migrate to different positions within the sediment matrix making the distance between the cells and the fluorometer probe variable and 
unknown. This leads to a variable attenuation of applied actinic light, as well as the fluorescence yields used to study aspects of photoacclimation. Furthermore, cells may migrate in response to darkness applied for measurement of dark adapted fluorescence parameters, again altering fluorescence yields (Sections 2, 3 and 6). These effects, and others discussed in this chapter, lead to potential errors in the application of variable chlorophyll fluorescence to migratory MPB biofilms. As a result great care is needed in the interpretation of fluorescence data obtained. Benthic diatom taxa, which can comprise the majority of MPB biomass, also show differences in photophysiology from higher plants, making conventional interpretation of fluorescence data incorrect. For example, diatoms exhibit high levels of down regulation through diadinoxanthin/diatoxanthin xanthophyll cycling, non-photochemical quenching (NPQ), induced as a result of the trans-thylakoid proton gradient resulting from light induced electron transport (Section 3). Thus MPB cells can show behavioural and physiological down regulation. However chlororespiration during dark periods leads to retention of this proton gradient, retaining NPQ in the dark (Section 3). This can suppress maximum fluorescence yield in the dark $(\mathrm{Fm})$ such that it is lower than operational maximum yield in low light (Fm'), making conventional calculation of NPQ from the difference in these yields problematic (Sections 3 and 5).

In this review, the authors have summarised the main areas of fluorescence research as applied to benthic biofilms, principally concentrating on those of intertidal soft sediment ecosystems. The methodology is summarised, along with potential problems, as well as ways to minimise error and achieve correct interpretation of data obtained. The review covers subsurface signal as a result of vertical integration of fluorescence measurements (Section 2), non-photochemical quenching and the xanthophyll cycle (Section 3), measurement and calculation of fluorescence derived 
electron transport rate (Section 5), methodology used to obtain light curve parameters of photophysiology, e.g. photoacclimation (Section 6) and concludes with a section comparing fluorescence to other methods including radio-labelled carbon uptake and oxymetry (Section 7).

\section{The effects of subsurface signal}

\subsection{Microphytobenthic biofilms on soft sediments}

Sediments colonised by microphytobenthos are optically dense, causing both downwelling light (including light generated by a fluorometer) as well as upwelling fluorescence to suffer from considerable attenuation within the microalgal biofilm/sediment matrix. As a result, the fluorescence levels $F_{\mathrm{s}}$ and $\mathrm{F}_{\mathrm{m}}$ ' measured near the surface represent the integration of the fluorescence signals emitted at various depths, distorting the relationship between $\mathrm{F}_{\mathrm{o}}$ and $\mathrm{chl} \mathrm{a}$ as this relationship will thus not only depend upon the total biomass, but also on the shape of the vertical biomass profile. Of more importance, this effect causes the measurement of the effective quantum yield, $\Delta \mathrm{F} / \mathrm{F}_{\mathrm{m}}$ ', at the surface to differ significantly from the true, inherent value of the microalgae composing the biofilm, because the relationship between $F_{s}$ and $\mathrm{F}_{\mathrm{m}}$ ' varies with irradiance within the depth range over which the fluorometer signal is integrated (Forster and Kromkamp 2004, Serôdio 2004).

The depth-integration effect was first predicted from observations of changes in $\Delta \mathrm{F} / \mathrm{F}_{\mathrm{m}}$ ' in undisturbed biofilms under constant irradiance (Underwood et al. 1999, Perkins et al. 2001, 2002), and was studied in detail using numerical simulation models (Forster and Kromkamp 2004, Serôdio 2004). Studies showed that fluorescence measurements taken non-invasively at the surface of the sediment result in a substantial light-dependent overestimation of the inherent value of $\Delta \mathrm{F} / \mathrm{F}_{\mathrm{m}}$, and 
relative electron transport rate, rETR, particularly important under supersaturating irradiances (Fig. 2.1). As a consequence, light curves derived from depth-integrated measurements are likely to appear to saturate at higher irradiances, or to be less photoinhibited when compared to the true physiological response of the biofilmforming microalgae. The contribution of sub-surface fluorescence signals also affect the determination of the light response of non-photochemical coefficient NPQ, which is expected to be underestimated under high light when measured non-invasively in intact biofilms (Forster and Kromkamp 2004, Serôdio 2004).

While this effect may occur, although to a lesser extent, in other optically dense samples such as thick leaves or macroalgal thalli (Forster and Kromkamp 2004, Serôdio 2004, Susila et al. 2004), in the case of microphytobenthos the problem is further complicated by the occurrence of comparatively large scale vertical migration by motile diatoms. In this case, it becomes highly difficult to interpret fluorescence yields from biofilms where the cells move vertically within the sediment matrix, since the subsurface signal emanates not only from cells at unknown depth, but at a variable depth in the sediment. Additionally, signal strength is proportional to the distance between the fluorometer probe and the cells themselves, thus vertical migration may increase or decrease measured yields, so making interpretation of changes in yield or calculation of photophysiological parameters difficult. For example, a decrease in both $\mathrm{F}_{\mathrm{m}}$ ' and $\mathrm{F}$ can be due to induction of NPQ down regulation on exposure to increasing PAR or to downward migration (negative phototaxis). It is often not possible to differentiate between the two processes using fluorescence methods. For this reason it can be prudent to use subsurface spectral reflectance for measurements such as biomass, see below, (Kromkamp et al. 2006, Morris et al. 2008) as the reflectance spectra are not influenced by NPQ. 
It is hard to avoid artefacts of tidally induced vertical migration and positive or negative phototaxis but the effects can be minimized by not taking measurements during the first and last hour of the emersion period when vertical migration is maximal. In addition it is better to minimize the effects of phototaxis by keeping the duration of measurements as short as possible (e.g. minimise the duration of light steps during rapid light curves, RLCs, see later). PSII quantum efficiency often stabilizes before true steady state fluorescence is reached (authors pers. obs).

The issue of the subsurface signal from the cells within the subsurface sediment has been investigated in considerable depth (Kromkamp et al. 1998, Perkins et al. 2002, Forster and Kromkamp 2004, Serôdio 2004, Jesus et al. 2006). Kromkamp et al. (1998) discussed the issue of microcycling of cells such that the fluorescence yield was obtained from a varied surface community over time and that this could explain the persistent high $\Delta \mathrm{F} / \mathrm{F}_{\mathrm{m}}$ ' at high incident irradiance. Perkins et al. (2002) reported over estimation of ETR in sediments due to subsurface signal from cells exposed to a lower light level than that applied at the surface and showed that the community composition could change during a light curve. In addition it appeared that the PSII signal was contaminated by PSI-fluorescence, shown by using a $680 \mathrm{~nm}$ bandpass filter compared to the more conventional $695 \mathrm{~nm}$ longpass filter. Underwood et al. (2005) used high resolution fluorescence imaging to report diel patterns in $\Delta \mathrm{F} / \mathrm{F}_{\mathrm{m}}$ ' of several benthic diatom species which showed microcycling over an artificially extended emersion period (Fig. 2.2). Serôdio (2004) and Forster and Kromkamp (2004) also demonstrated similar effects on measurements due to integration of the fluorescence signal over sediment depth. To make matters more complex, the degree of overestimation of $\Delta \mathrm{F} / \mathrm{F}_{\mathrm{m}}$, , which manifests the greatest at light levels above the light saturation coefficient, $E_{k}$, depends also on the shape of the 
biomass profile, and subsurface biomass maxima, resulting in the highest degree of overestimation of the true $\Delta \mathrm{F} / \mathrm{F}_{\mathrm{m}}$, , and hence resulting in an overestimate of the maximum electron transport rate, $\mathrm{rETR}_{\max }$, often by as much as of $60 \%$ (Forster and Kromkamp 2004). The effect of this on estimates of depth integrated primary production will be discussed later when comparing fluorescence with other methods used to estimate primary production.

Vertical migration does not only influence the apparent value of $\Delta \mathrm{F} / \mathrm{F}_{\mathrm{m}}$ ', but it also influences the measured minimal fluorescence yield, $F_{o}$ (Forster and Kromkamp 2004, Perkins et al. 2001, Jesus et al. 2006), which is used as a proxy of biomass (Barranguet and Kromkamp 2000, Honeywill et al 2002). It is thus not surprising that Jesus et al. (2006) observed that tidally induced vertical migration resulted in either an over estimation or under estimation of biomass dependent upon the time the measurements were made within the emersion period.

Recent work using migration inhibitors (Cartaxana et al. 2008, Perkins et al. in prep.) and engineered non-migratory biofilms (Jesus et al. 2006a,b; Mouget et al. 2008) have investigated these issues further and confirm that vertical migration and the concomitant "deep layer fluorescence" lead to erroneous estimates of quenching coefficients and overestimation of $\Delta \mathrm{F} / \mathrm{F}_{\mathrm{m}}$ '.

\subsection{Stromatolites - the effect of "layered" biofilms}

Stromatolites are perhaps an extreme example of a layered biofilm where subsurface cells "interfere" with the fluorescence signal from surface cells and vice versa. The measurements become an integrated measurement of the sub surface cyanobacteria (Figure 2.3) and the surface cells, where diatom epiphytes can be present (Fig. 2.4, Perkins et al. 2007). Stromatolites consist of a microbial consortium 
which trap ooids by extracellular polymers, mainly of cyanobacterial origin (Visscher et al. 1998, Reid et al. 2000). Reid et al. (2000) described 3 different developmental stages where the pioneering type 1 stromatolite has the lowest cyanobacterial diversity with Schizotrix gebeleinii as the dominant form. Type 2 is characterised by a micritic crust at the surface (often lacking diatom epiphytes, Kromkamp, pers. obs.) and in climax state type 3 the endolythic Solentia spp. bores into the ooids and fuses them together, giving the stromatolite its structure. Types 2 and 3 have the highest cyanobacterial diversity (Baumgartner et al. (2007). Figure 2.3 shows a typical example of a type 1 stromatolite (Kromkamp et al. 2007) with a clear subsurface layer, but the layer above also contain many cyanobacteria. This picture clearly highlights the difficulty when applying surface measurements using PAM fluorometry: the depth and thickness of the subsurface layer varies as well as the distance to the stromatolite surface. This means that quantitative analyses of both cyanobacterial biomass as well as effective quantum efficiency is very difficult as the apparent $\Delta \mathrm{F} / \mathrm{F}_{\mathrm{m}}$ ' and $\mathrm{F}_{\mathrm{o}}$ is integrated over an unknown depth interval with varying biomass distribution. This problem can be partly circumvented by measuring on a cross section by putting the PAM fiberoptics parallel to the mat surface (Perkins et al. 2007). However, this will disrupt chemical and light gradients, especially of oxygen and light, have greatly influence photosynthetic activity (Kromkamp et al. 2007).

The following example demonstrates the problems with working with cyanobacteria (Fig. 2.5). RLCs were made on two sections of the stromatolite where the depth of the subsurface layer was respectively at 4 and $1 \mathrm{~mm}$ below the surface. The layer above the surface contained cyanobacteria (cf. Schizotrix sp.) but the biomass was substantially lower than in the subsurface layer. After the RLCs were performed, the surface layer was removed until the subsurface layer was exposed and 
new RLCs were made. In both cases the measured rETR was much higher when the surface layers were not removed. Several explanations are possible: the cyanobacteria in the surface layer have a higher photosynthetic activity then cyanobacteria in the subsurface biomass maximum. Deeper in the stromatolite the oxygen concentration might be low, causing rapid inactivation of the stromatolite (Kromkamp et al. 2007, Perkins et al. 2007). This might be the case for the layer $4 \mathrm{~mm}$ below the surface but is unlikely for the layer $1 \mathrm{~mm}$ below the surface. Alternatively, fluorescence from the deeper layers, where the irradiance is lower and where $\Delta \mathrm{F} / \mathrm{F}_{\mathrm{m}}$ ' will thus be higher than at the stromatolite surface, will cause an overestimation of true $\Delta \mathrm{F} / \mathrm{F}_{\mathrm{m}}{ }^{\prime}$ of the cells at the surface. The degree of overestimation depends on the depth (and thus the irradiance) of the subsurface layer (which is unknown without destructive sampling) and on the biomass in the subsurface maximum relative to the cyanobacterial biomass in the upper layers. Because the RLCs on the exposed subsurface layers are rather similar, the contribution of "deep layer fluorescence" seems the most likely explanation for the higher rates of rETR measured at the stromatolite surface. A comparison with measurements on cross sections (Mouget et al. in prep) seems to corroborate this conclusion.

\subsection{Deconvolution of depth integrated signals}

The inherent photophysiological status of the microalgae comprising a biofilm can be estimated from depth integrated fluorescence measurements made on undisturbed samples. A method has been proposed to estimate the inherent light response through the deconvolution of light-response curves based on depthintegrated measurements (Serôdio 2004). This approach is based on the relationship existing between the depth-integrated fluorescence levels measured at consecutive 
light levels of a light curve and the depth attenuation of the fluorescence signal, which results in a set of recursive equations to be applied to depth-integrated light curves. This approach has assumptions and limitations (Serôdio 2004; Jesus et al. 2006): i) it assumes an homogeneous photophysiological light response for all the microalgae; ii) assumes an exponential vertical attenuation of incident actinic light and emitted fluorescence, which implies a vertically homogeneous photic zone; iii) it requires the attenuation coefficients for downwelling actinic light and upwelling fluorescence to be known; iv) it does not account for changes in surface biomass during the construction of the light curve on intact biofilms. Nevertheless, numerical simulations using published values for actinic light and fluorescence have shown a significant reduction in the differences between depth-independent light curves and those deconvoluted from depth-integrated curves (Serôdio 2004).

\section{Down regulation through Non Photochemical Quenching}

\subsection{NPQ and the Xanthophyll cycle in diatoms}

Diatoms of MPB biofilms are submitted to an extreme light environment which includes exposure to both high visible and UV irradiances, and fast and unpredictable light fluctuations. Additionally, other environmental pressures (nutrient limitation, extremes in temperature and salinity, etc.) can slow down the photosynthetic machinery and create a situation where the photosynthetically converted light energy cannot be entirely used for metabolic purposes (see Chapters 11 and 12). In order to maintain their photosynthetic productivity at an optimal level by preventing photoinhibition (i.e. decrease in quantum efficiencies $F_{v} / F_{m}$ and $\left.\Delta \mathrm{F} / \mathrm{F}_{\mathrm{m}}{ }^{\prime}\right)$, diatoms need to acclimate to environmental changes through fast regulation of their photosynthetic activity (Lavaud 2007). Together with the PS II electron cycle 
(Lavaud et al. 2002b), the non-photochemical quenching of chlorophyll fluorescence (NPQ) is believed to be one of the most important of these 'photoprotective' (or 'photoacclimative') mechanisms in diatoms (Lavaud 2007). Most of the diatoms of the MPB are able of vertical migration into the sediment as a behavioral photoprotective strategy in order to avoid excess light exposure at the surface (see above). However, vertical migration and NPQ appear to be complementary, NPQ induction may occur before the onset of the migratory response (Serôdio et al. in press, Underwood et al. 2005), although recent work using chemical inhibitors of migration and NPQ suggests that migration may be preferred to NPQ (Perkins et al. in prep.).

The NPQ mechanism is described in the Chapter 12 (paragraph 12.1). $\mathrm{qE}$, the energy-dependent quenching, which is regulated by the build-up of a transthylakoid proton gradient $(\Delta \mathrm{pH})$ and the operation of the xanthophyll cycle (XC) (Lavaud and Kroth 2006), remains the best known component and plays a major role in the regulation of the diatom NPQ. The machinery triggering and controlling the NPQ amplitude and kinetics is now well known (Goss et al. 2006, Lavaud 2007). The major characteristic of NPQ in diatoms is its amplitude (Lavaud et al. 2002, Ruban et al. 2004) such that it can account for up to $90 \%$ of energy dissipation (Lavaud et al. 2002). Estuarine species of the MPB diatoms show a higher (up to 5 times higher than plankton species, Fig. 3.1) and faster (10 s induction) switch on/off of NPQ (Serôdio et al. in press; Serôdio et al. 2005, 2006, Herlory et al. 2007, Lavaud et al. 2007, Cruz and Serôdio 2008).

The mechanism of NPQ in diatoms shows other specificities regarding the pigments and proteins that are involved as well as their spatial organization (see Lavaud 2007). In particular, the xanthophylls cycle, which consists of the enzymatic de-epoxidation/epoxidation of the couple DD-DT, is employed (Fig. 3.2, Lavaud 
2007). Accumulation of photoprotective diatoxanthin, DT, depends on the concomitant activity of two enzymes, a de-epoxidase and an epoxidase, the activity of which depends on the light intensity via the build-up of the transthylakoid $\Delta \mathrm{pH}$ and the availability of co-factors (Fig. 3.2A).

The regulation of the $\mathrm{XC}$ in diatoms shows some striking peculiarities, the main one being the triggering of the diadinoxanthin, DD, de-epoxidase by a weak $\Delta \mathrm{pH}$ (and thus a rather high lumen pH, Fig. 3.2B) (Jakob and Wilhelm 2001) so that the DD de-epoxidation already occurs at lower irradiances and shorter illumination times than in higher plants (Fig. 3.2B). Additionally, MPB diatoms can react to high light stress by accumulating large amounts of DD-DT (Rech et al. 2005, van de Poll et al. 2006, Schumann et al. 2007) in order to increase their photoprotection capacity via NPQ (Perkins et al. 2006, Schumann et al. 2007, Cruz and Serôdio 2008). All together, these differences in the regulatory components and mechanistic components of the NPQ process in diatoms have been suggested to ensure more flexibility and thus quicker response to the light environment (Lavaud 2007).

Field experiments have shown that the photoprotection ensured by both the XC and NPQ are essential for the MPB diatoms to maintain an optimal photosynthetic activity (Serôdio et al. 2005), even if not $100 \%$ efficient (Serôdio et al. in press). Additionally, the differential ability of species to cope (including NPQ) with prolonged high light and UV (Waring et al. 2006) is believed to potentially control spatial distribution (Fig. 3.1) (Lavaud et al. 2007) as well as species succession within MPB biofilms (Tuji 2000, Serôdio et al. 2005, Underwood et al. 2005).

As described later in this chapter, RLCs have become a powerful approach to estimate the photosynthetic productivity and the photophysiology of MPB assemblages isolated from the field or directly in situ. Nevertheless, the assessment of 
NPQ on MPB via RLCs is rendered problematic by the confounding effects on $F_{m}$ and $\mathrm{F}_{\mathrm{m}}$ ' levels of 1) downward vertical migration of the cells in the sediment, 2) the light and fluorescence attenuation in the upper layers of the sediment, 3) the contribution of fluorescence originating in "deeper" layers with a concomitant lower irradiance, and 4) a sustained NPQ under prolonged darkness (see Serôdio et al. 2005, Jesus et al. 2006b). In order to solve this problem, Serôdio and co-workers proposed to assess NPQ following $\Delta \alpha_{R L C}$, which is the variation of the initial slope of RLC under high light exposure. $\alpha_{\text {RLC }}$ indeed linearly correlates with NPQ irrespective of measurement conditions, e.g. ex situ/in situ, summer/winter, low light/high light acclimation, etc. (Serôdio et al. 2005, 2006, in press, Cruz and Serôdio 2008) making it a good alternative to the classic calculation of NPQ as $\left(\mathrm{F}_{\mathrm{m}}-\mathrm{F}_{\mathrm{m}}{ }^{\prime}\right) / \mathrm{F}_{\mathrm{m}}{ }^{\prime}\left(\right.$ or $\left(\mathrm{F}_{0}-\mathrm{F}_{0}{ }^{\prime}\right) / \mathrm{F}_{0}$, , see Fig. 3.3A) (discussed in Serôdio et al. 2006). Additionally, it has recently been reported that RLC construction itself can generate rapid endogenous changes of the photosynthetic activity which in turn modulates chl a fluorescence emission, and can potentially affect the ETR measurement and subsequent derivation of photophysiological parameters (Perkins et al. 2006, Cruz and Serôdio 2008). Together with the redox state of $\mathrm{Q}_{\mathrm{A}}$, NPQ has been shown to be one the main endogenous mechanisms potentially disturbing chl a fluorescence emission (Perkins et al., 2006; Jesus et al., 2006b; Herlory et al., 2007).

There are a number of physiological/technical features which can strongly influence NPQ amplitude and kinetics, and subsequently the shape of RLCs in MPB communities dominated by diatoms: 1) the species composition (Perkins et al. 2002, Serôdio et al. 2005, Underwood et al. 2005), 2) the light/dark past history of the cells and hence the cells photoacclimation state (Perkins et al. 2006, Cruz and Serôdio 2008), 3) the accumulated light dose during the RLCs (Perkins et al. 2006, Herlory et 
al. 2007 Cruz and Serôdio 2008), 4) the fluorometer used (Perkins et al. 2006, Cruz and Serôdio 2008). Figure 3.3 shows that, in the MPB diatom species Navicula phyllepta, the length of each irradiance step $(10,30,60$ or 140 s) can influence partly the level of NPQ induction (Fig. 3.3A), the profile of RLCs (Fig. 3.3B) and the subsequent determination of ETR $\mathrm{max}_{\max }$ as a function of the light history of the cells (Fig. 3.3C). However, it should be mentioned that this phenomenon is not always observed on intact MPB communities in situ as shown in Fig. 3.4.

\subsection{NPQ in the dark}

In diatoms, NPQ occurs not only during light exposure but also during prolonged darkness (several hours; Jakob et al. 1999, Consalvey et al. 2004, Serôdio et al. 2005). Dark NPQ is due to chlororespiration, the amplitude of which is especially high in diatoms (Dijkman and Kroon 2002, Lavaud et al. 2002b). This pathway allows electrons to flow from the NADPH, $\mathrm{H}^{+}$to $\mathrm{O}_{2}$, both synthesized in light, via the plastoquinone (PQ) pool: it is the respiratory chain of the plastids (Kuntz, 2004). In diatoms, the chlororespiratory pathway is switched on very rapidly after the onset of darkness (Dijkman and Kroon 2002). Its amplitude and duration directly relates with the irradiance and duration of the former illumination through accumulation of reducing equivalents (Lavaud et al., 2002b), in other words it depends on the past light history of the cells (Cruz and Serôdio 2008). By transferring electrons through PQ, the chlororespiratory pathway generates in darkness the buildup of a transthylakoid $\Delta \mathrm{pH}$ (Ting and Owens 1993). This dark $\Delta \mathrm{pH}$ has been shown to be sufficient to activate the DD de-epoxidase and to drive the synthesis of DT, and the development of a large NPQ (up to 2) (Jakob et al. 1999, Jakob and Wilhelm 2001; Serôdio et al., 2005, 2006). This is only possible because in diatoms, as specified above (Fig. 3.2B), the DD de-epoxidase needs only a weak acidification of the lumen 
to be activated, even though the rate of chlororespiration and subsequent change in the $\Delta \mathrm{pH}$ are low (Jakob and Wilhelm 2001). Such a process would allow the cells to prevent photoinhibition during a subsequent sudden exposure to high light by keeping activated the dissipative function of the LHC system; an obviously adaptive advantage for the diatom species growing in a fluctuating light environment. Dark NPQ is even more physiologically relevant for diatoms of the MPB which can spend more than $18 \mathrm{~h}$ per day in the dark in the sediment before migrating to the surface and experiencing high light exposure (Serôdio et al. 2005).

As well as the NPQ which develops in light, the dark NPQ generates a methodological problem due to our inability to instantaneously measure the 'true' $\mathrm{F}_{\mathrm{m}}$ (and $\mathrm{F}_{0}$ ) level during dark-adaption of the cells in situ where their past light/dark history is usually unknown. Indeed, to achieve correct measurement of fluorescence parameters, complete $\mathrm{Q}_{\mathrm{A}}$ oxidation and NPQ relaxation are required, which is usually reached after a short (15 min) dark-adaptation in controlled laboratory conditions but which might not be enough in situ (Perkins et al. 2001, Consalvey et al. 2004, Jesus et al. 2006a). Dark NPQ can easily quench $F_{m}$ by at least $10-15 \%$ depending on the diatom species (Jakob and Wilhelm 2001). When the cells are further exposed to a low irradiance (below $150 \mu \mathrm{mol}$ photons $\mathrm{m}^{-2} \mathrm{~s}^{-1}$, Mouget and Tremblin 2002) during the measurement following dark-adaptation (typically at the beginning of RLCs acquisition), the whole photosynthetic machinery is fully activated which 1) reoxidizes $\mathrm{Q}_{\mathrm{A}}$ and the PS II, 2) dissipate the $\Delta \mathrm{pH}$ and subsequently change the equilibrium of the $\mathrm{XC}$, hence relaxing the fluorescence quenching (Consalvey et al. 2004, Serôdio et al. 2005, 2006). Hence, it is rather common to observe $F_{m}$ ' level transiently higher than the dark $F_{m}$ level (Mouget and Tremblin 2002, Consalvey et al. 2004, Serôdio et al. 2005, 2006). As a consequence it significantly affects the 
measurement and calculation of many fluorescence parameters. It can also significantly perturb the use of $\mathrm{F}_{0}$ and its changes as a proxy for the dynamics of MPB diatom biomass at the surface and within the sediment (Consalvey et al. 2004, Jesus et al. 2006a). Solutions have been proposed to rule this problem out: 1) measurement of the 'true' $F_{m}$ level in the presence of DCMU which is only applicable in controlled laboratory conditions (see Chapter 12, paragraph 12.4), 2) short exposure to low dose of far-red or low light instead of dark-adaptation in order to reoxidize PS II and dissipate the $\Delta \mathrm{pH}$ and NPQ (Consalvey et al. 2004, Jesus et al. 2006a), 3) use $\mathrm{F}_{\mathrm{m}}$ ', $\mathrm{m}$, the maximum $F_{m}$ ' value measured as the 'true' $F_{m}$, instead of the dark $F_{m}$ level (Serôdio et al. 2006, in press, Cruz and Serôdio 2008).

\section{The quantification of the microalgal biomass using fluorescence}

The quantification of the microalgal biomass of microphytobenthos biofilms is a methodological challenge, due to the thinness of the sediment photic zone, the large horizontal heterogeneity, and the rapid changes in microalgae near the surface due to vertical migratory movements. Serôdio et al. (1997) was the first study to investigate the possibility of using in vivo chlorophyll fluorescence to non-destructively quantify the microalgal biomass of microphytobenthos biofilms. They experimentally established a linear relationship between sediment chlorophyll a (chl a) content and minimum fluorescence yield $F_{o}$, showing that large $F_{o}$ variations in the dark represented changes in the amount of microalgae at the sediment surface, as the result of cell vertical migratory movements. The use of $F_{o}$ as a biomass proxy was shown to be preferable to other fluorescence parameters such as $F_{m}$ or $F_{m}$ ' because it varied the least with previous light history, temperature and microalgal group. $\mathrm{F}_{\mathrm{o}}$ was shown to allow the estimation of the miroalgal biomass present in the photic zone of the 
sediment (defined as 'photosynthetically active biomass'; Guarini et al. 2000, Honeywill et al. 2002) but also of the microalgal biomass in the photic zone weighted by its contribution to depth-integrated photosynthesis (defines as 'producitve biomass'; Serôdio et al., 2001). This method allowed to overcome the operational difficulties with previously used methods, based on destructive and time-consuming procedures, and introduced considerable operational advantages, including the possibility to obtain repeated measurements in the same sample over time, without any physical disturbance of the sediment-air or -water interface, and allowing the concurrent measurement of other variables in the same sample (Serôdio et al. 1997).

However, the determination of $F_{o}$ in MPB biofilms is not without problems and has been the source of significant discussion (e.g. Consalvey et al. 2004, Jesus et al 2006b,c). These problems are related to MPB vertical movements during the dark adaptation (DA) period and to problems concerning the presence of NPQ in the dark (exhibited by diatom dominated biofilms). The determination of fluorescence parameters requiring dark-adaptation $\left(\mathrm{F}_{\mathrm{o}}\right.$, as well other parameters and indices such as $\mathrm{F}_{\mathrm{m}}$ or $\left.\mathrm{F}_{\mathrm{v}} / \mathrm{F}_{\mathrm{m}}\right)$ requires that PSII reaction centres and $\mathrm{Q}_{\mathrm{A}}$ be in their fully oxidised form (Schreiber et al. 1986). To achieve this state it is conventional to place samples in full darkness until a dark adaptation steady state is reached. However, dark adapting microphytobenthic biofilms present a number of specific problems unique to this type of community.

Microphytobenthic biofilms are know to exhibit a behavioural photoregulation mechanism where microalgae migrate vertically within the sediment matrix as a response to changes in ambient light in order to maintain an optimum light environment and avoid photo-inhibition (e.g. Perkins et al. 2002; Jesus et al. 2006b,c). This response to changes in ambient light can hinder the determination of $F_{o}$ if 
vertical migration occurs during the dark adaptation period necessary for $\mathrm{Q}_{\mathrm{A}}$ and PSII re-oxidation. This has been recognized as a potential problem since the first studies using fluorescence (e.g. Serôdio et al. 1997) and short adaptation periods have been suggested as alternatives. Several forms of determining the minimum fluorescence yield have been tested, depending on the length of dark-adaptation used $\left(\mathrm{F}^{\prime}, \mathrm{F}_{\mathrm{o}}{ }^{\prime}, \mathrm{F}_{\mathrm{o}}{ }^{2}\right.$, $\mathrm{F}_{\mathrm{o}}{ }^{5}, \mathrm{~F}_{\mathrm{o}}{ }^{10}, \mathrm{~F}_{\mathrm{o}}{ }^{15}$; the superscript number denoting the duration of the dark period in minutes). By far, the most commonly used parameter is $\mathrm{F}_{\mathrm{o}}{ }^{15}$ (Kromkamp et al,1998; Underwood et al. 1999; Barranguet and Kromkamp 2000; Perkins et al. 2001; Hagerthey et al. 2002; Honeywill et al. 2002; Underwood 2002; Consalvey et al. 2004; Defew et al. 2004; Jesus et al. 2006b,c ), followed by 5 min (Serôdio et al 1997, 2000, 2001, 2003; Jesus et al. 2006b,c) and 2 min (Serôdio et al. 2006, 2007 and 2008). However, the 15 min of DA can be excessive in some biofilms inducing significant downward migration during that period (e.g. Jesus et al. 2006a, b and c), suggesting that shorter time periods might be preferable. In fact, Jesus et al. (2006c) compared the relationship between chl a with $\mathrm{F}_{\mathrm{o}}{ }^{\prime}, \mathrm{F}_{\mathrm{o}}{ }^{5}$ and $\mathrm{F}_{\mathrm{o}}{ }^{15}$ and found no significant differences from $\mathrm{F}_{\mathrm{o}}{ }^{\prime}$ to $\mathrm{F}_{\mathrm{o}}{ }^{15}$ in muddy sediment assemblages, suggesting that light history had little or no effect in the epipelic assemblages and that no DA was necessary for a good relationship between chl a and fuorescence. However, in sandy sediments there was evidence of a light history effect and a 5 min DA period was necessary to remove this effect. Other authors (e.g. Serôdio et al. 2007) have found that shorter DA times (2 min) might be even better than 5 min for the determination of photosynthesis fluorescence indices that require the input of a minimum fluorescence yield parameter.

Intertidal biofilms exhibit the additional problem of not showing an homogeneous behavioural response to light stimulus throughout the tidal cycle, i.e. 
biofilms close to the beginning of the emersion period will tend to increase $F_{o}$ values during the DA period as a result of cells migrating to the sediment surface, and

measurements close to the end of the emersion period will be very sensitive to darkness and cells will migrate downwards quickly over the DA period. Although, this does not seem to be the case in all estuaries (e.g. Kromkamp et al,1998; Barranguet and Kromkamp 2000; Hagerthey et al. 2002; Honeywill et al. 2002;). To reduce this problem it was proposed that measurements are taken closer to the middle of the emersion period and that a low light or far-red treatment is used instead to the dark treatment (Jesus et al. 2006b). It is not clear why low light and far-red light work similarly but both treatments have to be applied at a reduced photon flux quantity to work properly. Thus, it is possible that this reduced photon flux promotes the dissipation of the chlororespiration trans-thylakoid proton gradient ( $\square \mathrm{pH}$ ) exhibited by diatoms in the dark (Ting and Owens, 1993, Dijkman \& Kroon, 2002; Lavaud et al., 2002). The reduction in the $\Delta \mathrm{pH}$ promotes the exoxidation of diatoxanthin into diadinoxanthin. Therefore, decreasing the NPQ caused by diatoxanthin presence in the dark (Jakob et al. 1999, Jakob and Wilhem 2001). Another advantage of low light is that it seems to promote the presence of cells at the surface thus reducing the problem of migration downwards that occurs during the dark adaptation period (Jesus et al. 2006b).

\section{Calculation of electron transport rate: ETR $v$ rETR}

\subsection{Multiple and single turnover methods}

The rate of electron transport by PSII depends on the amount of light absorbed by the antenna of PSII and the efficiency at which the absorbed light by PSII is used by the reaction centers (RCII) to drive charge separation. Basically two methods are used which are both based on the light doubling method originally proposed by 
Bradbury and Baker (1981) which we will call the Multiple- turnover (MT) method and the single turnover (ST) method and which relate to the description of the pulseamplitude modulation principle by Schreiber et al. (1986) and the pump and probe method (Falkowski et al. 1986b) respectively. The differences between these two approaches have recently been reviewed by Kromkamp and Forster (2003).

\subsection{The MT-method.}

The MT-method is usually used by scientists using the PAM family of fluorometers which uses a multiple turnover flash to measure the quantum efficiency of PSII. Because the flash duration used to measure the maximum fluorescence $\left(\mathrm{F}_{\mathrm{m}}\right)$ is relatively long (50ms - $1 \mathrm{sec})$ it allows for multiple charge separations during the flash and will thus lead to fully reduced $\mathrm{Q}_{\mathrm{A}}, \mathrm{Q}_{\mathrm{B}}$ and PQ-pool. When the PSII effective quantum efficiency $\left(\Delta \mathrm{F} / \mathrm{F}_{\mathrm{m}}{ }^{\prime}\right)$ is measured the absolute rate of electron transport per unit area $\left(\mathrm{ETR}^{\mathrm{A}}\right)$ can be calculated as follows:

$$
\mathrm{ETR}^{\mathrm{A}}=\mathrm{E} \cdot \mathrm{A}_{\mathrm{II}} \cdot \Phi_{\mathrm{RC}} \cdot \Delta \mathrm{F} / \mathrm{F}_{\mathrm{m}}
$$

$\mathrm{A}_{\mathrm{II}}$ is the fraction of the incident light (E) which is absorbed by PSII. $\Phi_{\mathrm{RC}}$ is yield (in electrons) of reduced $\mathrm{Q}_{\mathrm{A}}$ per trapped photon, i.e. the maximum quantum yield of photochemistry within PSII, and it is usually assumed to be equal to 1 (Kolber and Falkowski 1993). Note that $\mathrm{ETR}^{\mathrm{A}}$ is expressed in $\mu \mathrm{mol}$ electrons s $\mathrm{s}^{-1} \mathrm{~m}^{-2}$ of surface area. When working with higher plants it is assumed that leaves absorb approx. $85 \%$ of incident light, and about half of this is partitioned to PSII. Assuming that $\Phi_{\mathrm{RC}}$ is close to 1 , eq. (1) can be rewritten as: 
Often the fraction of absorbed light is determined by measuring the transmittance of light through a piece of macroalgal thallus using a light sensor (Beer et al. 1998, Longstaff et al. 2002). Implicit in this assumption is that the measured signal is equivalent to the integrated fluorescence yield over the entire path length, an assumption which might not be met, certainly when several cell layers are involved. The artefacts associated with this assumption were discussed in chapter 3 where the effects of "deep layer" fluorescence are described.

When working with optically thin suspensions of phytoplankton or unicellular algal cultures a slightly different approach is taken: in this case the ETR is usually calculated per mg chl a $\left(\mu \mathrm{mol} \mathrm{e} \mathrm{e}^{-}(\mathrm{mg} \operatorname{chl~a})^{-1} \mathrm{~s}^{-1}\right)$ :

$$
\mathrm{ETR}=\mathrm{E} \cdot \mathrm{a}{ }^{*}{ }_{\mathrm{PSII}} \cdot \Delta \mathrm{F} / \mathrm{F}_{\mathrm{m}} \cdot \Phi_{\mathrm{RC}}
$$

Where $\mathrm{a}{ }^{*}$ PSII is the optical absorption cross section of PSII (here expressed in $\mathrm{m}^{2}(\mathrm{mg}$ chl a) $)^{-1}$, which is the product of the cross section of a single PSII unit and the number of PSII per mg chl $\left(\mathrm{a}^{*}{ }^{*}\right.$ PSII $\left.\left.=\mathrm{a}^{*}{ }_{\text {PSII }} \cdot \mathrm{n}_{\text {PSII }}\right)\right)$. As it is rather difficult to measure the absorption cross section of PSII it is normally assumed that a ${ }^{*_{\text {PSII }}}$ is half the optical cross section of the cells $\left(\mathrm{a}^{*} \mathrm{~m}^{2}(\mathrm{mg} \mathrm{chl} \mathrm{a})^{-1}\right.$, i.e. it is assumed that $50 \%$ of the absorbed light is funneled to PSII and the other half to PSI). Below we will discuss this assumption. Thus, assuming $\Phi_{\mathrm{RC}}$ equals 1 we can rewrite eq. $3 \mathrm{a}$ as:

$$
\mathrm{ETR}=\mathrm{E} \cdot \mathrm{a}^{*} \cdot 0.5 \cdot \Delta \mathrm{F} / \mathrm{F}_{\mathrm{m}}
$$


The optical cross section can be easily determined using a spectrophotometer equipped with an integrating sphere, i.e. by using the filterpad method for natural phytoplankton which requires concentration on a filter before the absorption measurements can be made (Tassan and Ferrari 1998, Simis et al. 2005).

\subsection{The ST-method}

Researchers using a saturating single turnover flash to measure $\mathrm{F}_{\mathrm{m}}$ ' usually take the approach developed by Falkowski et al. (1986b) and Kolber and Falkowski (1993), based on the development of the pump and probe fluorometer, which was followed up by the Fast Repetition Rate Fluorometer (FRRF) (Kolber et al. 1998). Here the rate of photosynthetic electron transport is described as follows:

$$
\mathrm{ETR}=\mathrm{E} \cdot \mathrm{a}^{*}{ }_{\text {PSII }} \cdot \mathrm{n}_{\mathrm{PSII}} \cdot \mathrm{q}_{\mathrm{P}} \cdot \Phi_{\mathrm{tm}} \cdot \Phi_{\mathrm{RC}} \cdot \mathrm{f}
$$

Here $\mathrm{a}^{*}{ }_{\text {PSII }}$ is the optical cross section of a single PSII unit $\left(\mathrm{m}^{2} / \mathrm{mol}\right.$ PSII) and $\mathrm{n}_{\text {PSII }}$ is the number of PSII units per mg chl a, usually to be assumed equal to 0.002 (thus assuming $500 \mathrm{chl}$ a molecules per PSII (Falkowski 1981, Kolber and Falkowski 1993). The photochemical quenching coefficient $\mathrm{q}_{\mathrm{P}}$ (moles electrons transferred per mole photons absorbed by PSII) reflects the proportion of oxidized PSII centers and is often used as a proxy of the number of open reaction centers. This is, however, only true when the PSII centers are not connected (Kramer et al. 2004). The trapping efficiency $\Phi_{\mathrm{tm}}$ is the efficiency at which trapped photons in the pigment bed are transferred to an open RCII and $\mathrm{f}$ is the fraction of functional PSII centers. The product of the optical PSII cross section and the trapping efficiency equals the effective PSII cross section $\left(\sigma_{\text {PSII }}\right.$, units $\left.\mathrm{m}^{-2}(\mathrm{~mol} \mathrm{PSII})^{-1}\right)$ : 


$$
\sigma_{\mathrm{PSII}}=\mathrm{a}^{*}{ }_{\mathrm{PSII}} \cdot \Phi_{\mathrm{tm}}
$$

As the FRRF can measure the functional cross section $\sigma_{\mathrm{PSII}}$ from the rise of $F$ to $\mathrm{F}_{\mathrm{m}}$ during the induction flashlet sequence, eq. 4 can be rewritten as

$$
\mathrm{ETR}=\mathrm{E} \cdot \sigma_{\mathrm{PSII}} \cdot \mathrm{n}_{\mathrm{PSII}} \cdot \mathrm{q}_{\mathrm{P}} \cdot \Phi_{\mathrm{tm}} \cdot \mathrm{f}
$$

Eq. 6 is the one that is proposed by Kolber and Falkowski (1993) and Kolber et al. (1998) for use with the pump and probe and FRR fluorometer. The fraction of inactive centers (f) was measured as $\Phi_{\text {sat }} / 0.65$, where $\Phi_{\text {sat }}$ is the maximum PSII efficiency measured and 0.65 the assumed maximum PSII efficiency of healthy cells without non-functional PSII centers. Kromkamp and Forster (2003) argued that this factor should be omitted because non-functional PSII centers will affect the level of $\mathrm{F}_{\mathrm{o}}{ }^{\prime}$, and this is already incorporated in the value of $\mathrm{q}_{\mathrm{p}}$.

\subsection{Assumptions and uncertainties.}

Fraction of light absorbed by PSII. Both the MT as well as the ST method usually use a number of a-priori assumptions. When using the MT method to calculate ETR it is necessary to know which fraction of the absorbed light is funneled to PSII. Using a combination of optical and biophysical techniques. Suggett et al. (2004) tested the hypothesis that about $50 \%$ of the light is absorbed by PSII. For a large range of species (diatoms, green alga, haptophytes and a cryptophyte) the fraction of light absorbed by PSII varied between 0.48 and 0.58 , justifying this assumption. However, in the pelagophyte Aureococcus anophagefferens the PSII-antenna 
absorbed about $36 \%$ of the light and in two cyanobacterial Synechoccocus species PSII absorbed $25-32 \%$ of the total light. Interestingly, the fraction of light absorbed by PSII was independent of the growth irradiance. A similar approach was taken by Johnsen and Sakshaug (2007), but they used a slightly different scaling procedure to match the fluorescence excitation spectra to the absorption spectra in order to arrive at the fraction of light absorbed by PSII: their results show that $48-88 \%$ of the light absorbed by the photosynthetic pigments was absorbed by PSII, which is generally higher than the estimates obtained by Suggett et al. (2004). Whether this difference is entirely due to methodological question or to growth conditions and different algal species remains an open question, but clearly this topic requires further research.

Estimates of the number of PSII. When using the ST protocol the absorption is quantified by multiplying the measured functional cross section $\sigma_{\mathrm{PSII}}$ with the $\mathrm{n}_{\mathrm{PSII}}$. This latter factor is also rather difficult to measure, certainly using field material, and for this reason it is assumed that $\mathrm{n}_{\text {PSII }}$ equals 0.002 , i.e. a PSII contains $500 \mathrm{~mol} \mathrm{chl} \mathrm{a}$ (mol PSII $^{-1}$ (Kolber and Falkowski, 1993), a value based on the determinations by the photosynthetic unit (PSU) size by Mauzerall and Greenbaum (1989). Assuming that a PSU contains 4 RCII it can be calculated from the data presented by the references in Table 1 that generally $\mathrm{n}_{\mathrm{PSII}}$ varies between $500-725 \mathrm{~mol}$ chl a per mol PSII, although lower values have been reported for Isochrysis galbana.

Photoacclimation generally results in more $n_{P S I I}$ when the cells are grown in low irradiances (Table 1). Interestingly, Kromkamp and Limbeek (1993) observed that when the marine diatom Skeletonema costatum was grown in fluctuating light simulating vertical mixing, this resulted in smaller but more $\mathrm{n}_{\mathrm{PSII}}$. This makes sense as it allows the cells to both harvest the same amount as light as with large PSU, but it will result in a higher rate of maximal photosynthesis. Recently Suggett et al. (2004) 
compared estimates of $\mathrm{n}_{\mathrm{PSII}}$ obtained using the $\mathrm{ST}$ turnover oxygen measurements with a those obtained from a biooptical: $\mathrm{n}_{\text {PSII }}=\sigma_{\text {PSII }} / a^{*}{ }_{\text {PSII }}$ they observed a linear 1:1 relationship between both methods and for most eukaryotic algae $\mathrm{n}_{\text {PSII }}$ varied between 500-600 mol chl a per mol PSII. The pelagophyte A. anophagefferens had a larger $n_{\text {PSII }}$ and cyanobacteria seem to contain smaller $n_{\text {PSII }}(240-280$ mol chl a per mol PSII).

Uncertainties in $\sigma_{P S I I}$. Although the FRRF technique allows estimation of the measurement of the functional PSII cross section, it is necessary to stress that LED's (mainly blue) are used to induce the fluorescence induction curve from which $\sigma_{\text {PSII }}$ is estimated. Without spectral correction of the effective absorption of the FRRF in relation to the underwater light field, this may lead to an overestimation of $\sigma_{\text {PSII }}$ (Suggett et al., 2001).

\subsection{Calculation of ETR in microphytobenthos studies}

Most research measuring ETR on MPB or macroalgae have used a PAM-type fluorometer because a commercially available FRR-type fluorometer (such as Chelsea's Fast ${ }^{\text {Tracka }}$ or Satlantic's FIRe) that are able to measure $\sigma_{\text {PSII }}$, have not been available (RandD versions of both instruments have however been used for coral reef research). As is clear from the above section on the MT-protocol, calculation of absolute rates of PSII electron transport requires knowledge of incident irradiance and the optical absorption cross section, and this is exceedingly difficult when working on benthic biofilms. For this reason often the relative rate of ETR (rETR) is calculated as $\Delta \mathrm{F} / \mathrm{F}_{\mathrm{m}}{ }^{\prime} \cdot \mathrm{E}$. Because the value of $\mathrm{a}^{*}$ will change as a result of photoacclimation (time scales of change are hours-days because they related to de-novo synthesis or breakdown of pigments) it is not always possible to compare rates of rETR between publications. 
Morris and Kromkamp (2003) cultured the benthic diatom Cylindrotheca closterium at two different growth rates and compared the relationship between ETR and oxygen evolution at a range of different temperatures during steady state growth. In general they observed that the relationship between ETR and oxygen evolution was not very sensitive to short-term changes in temperatures. However the relationship of rETR versus oxygen evolution was rather different between low and high growth rate, but when they examined the relationship on the basis of absolute ETR, the differences were minor. This was due to the $\mathrm{a}^{*}$ values of the two cultures being different between the two growth rates. Nevertheless, often changes in rETR reflect changes in absolute ETR (Fig. 5.1): three out of the four different algal species showed a similar pattern in change in $\mathrm{rETR}_{\max }$ and absolute $\mathrm{ETR}_{\max }$ (expressed per cell), despite large changes occurring in the photosynthetic physiology after transfer from replete to a P-free medium. The exception was Emiliania huxleyi which showed an unexpected increase per cell, because the optical absorption cross section per cell increased. If the absolute ETR was expressed per unit chl a all cells showed a good correlation between the changes in rETR and ETR (data not shown). This suggests that with some care it maybe possible to deduce changes in photophysiology from relative rates of ETR, but definitely more research is needed to confirm this.

A possible way to obtain MPB cells in order to measure $\mathrm{a}^{*}$ spectrophotometrically would be to use the lens tissue method: however, this will only select for (a fraction) of the migrating species and the observed $a^{*}$ value might not be representative for the total MPB community. In order to avoid this problem Morris et al. (2008) reconstructed $\mathrm{a}^{*}$ from HPLC pigment analyses using the procedure of Bidigare, (1990) and compared the absorption values to the ones measured using the filterpad method. From this it was concluded that the package 
effect reduced the maximum absorption spectra obtained from the HPLC data by about 30\%, in line with other studies on MPB (Mercado et al., 2004) and phytoplankton (Berner et al., 1989; Johnsen and Sakshaug, 2007) although Nelson et al. (1993) reported that less than $25 \%$ of the phytoplankton in Californian coastal waters showed a measurable package effect. Using the reconstructed and measured $a^{*}$ values Morris et al. (2008) demonstrated that the PAM derived quantum efficiencies for C-fixation $\left(\Phi_{\mathrm{C}}\right)$ on both intact diatom biofilms as on sediment slurries with defined optical conditions matched the measured $\Phi_{C}$ very well. Only when growth rate of the diatom biofilm slowed down when the biomass reached an apparent steady state did the PAM derived $\Phi_{C}$ of the biofilm overestimate the measured $\Phi_{C}$ of the sediment slurry, whereas $\Phi_{C}$ of the slurry matched the measured $\Phi_{C}$. Most likely the overestimate of the true $\Phi_{\mathrm{C}}$ was caused by fluorescence derived from deeper layers (see above). This suggest that quantification of ETR on MPB biofilms is possible using reconstructed $\mathrm{a}^{*}$ values from HPLC derived pigments, provided the diatoms in the biofilm are actively growing and the biofilm does not reach a high biomass.

\section{Light response curves}

\subsection{A brief overview of methodology}

Light response curves (the photosynthesis - irradiance curve following Falkowski and Raven (1997)) are used to determine a range of photophysiological and productivity parameters. Incremental increases or decreases in the actinic light environment (PAR, usually applied by the flourometer in use) are applied, with measurement of the quantum efficiency $\left(\Delta \mathrm{F} / \mathrm{F}_{\mathrm{m}}{ }^{\prime}\right)$. The well known and accepted equations for calculation of ETR are applied and the resulting values plotted as a function of PAR. The result is a saturating curvilinear response, encompassing a near 
linear light limited phase, a light saturated phase and then and, in some instances, a third phase which is not always present and often attributed to down regulation/photoinhibition. Various methods of curve fitting have been applied to this curve, from which physiological parameters can be derived, including the method of Eilers and Peeters (1988) followed by curve fitting such as that following the NelderMead model (Press et al., 2003). Parameters derived are usually:-

1. $r E T R_{\max }$ - the maximum relative electron transport rate when light becomes saturating.

2. $\alpha$ - the maximum light use coefficient

3. $E_{\mathrm{k}}$ - the light saturation coefficient, calculated as $\mathrm{rETR}_{\max } / \alpha$

4. $\beta$ - the coefficient of down regulation / photoinhibition

These parameters, except $\beta$, along with the PAR at which saturation occurs (Es) can be calculated using the parameters derived from various models such Eilers and Peeters (1988).

The application of the methodology to benthic biofilms has been reviewed in Consalvey et al. (2005), but here it will be discussed principally to compare the three main types of light response curves: steady state light curves (SS), rapid light curves (RLC) and non-sequential light curves (NSLC). Light curve parameters ( $\mathrm{rETR}_{\max }, \alpha$ etc.) are mostly interpreted in similar ways for all light curves, except for the coefficient $\beta$. In SS light curves the decline in ETR indicated by the value of $\beta$ is attributed to photoinhibition, whereas in RLCs $\beta$ is a measurement of down regulation as the short duration of the light curve is not thought sufficient to induce photoinhibition (White and Critchley 1999). The other parameter worth mentioning here is $\mathrm{rETR}_{\max }$, where the subscript (r) preceding ETR denotes whether the measurement is of "relative" electron transport rate, i.e. in the absence of any 
measurement of the light absorption coefficient a* (Sakshaug et al. 1997, Beer et al. 2001, Forster and Kromkamp 2004, Perkins et al. 2006). In most instances measurement of a functional value of $\mathrm{a}^{*}$ is highly problematic for benthic biofilms, due to interference from the sediment matrix and the time required for measurement (see elsewhere in this chapter for more detail). As a result the majority of work has used rETR and hence determined $\mathrm{rETR}_{\max }$. Data are often considered to be comparative as a result of this relative measurement, as opposed to absolute values for comparison to other measurements of productivity (e.g. ${ }^{14} \mathrm{C}, \mathrm{O}_{2}$ described later in this chapter).

\subsection{Steady sate light curves}

Steady state (SS) light curves are those where the operational fluorescence yield ( $\mathrm{F}$ or $\left.\mathrm{F}^{\prime}\right)$ is allowed to reach a stable value after each incremental increase / decrease in PAR (Falkowski and Raven 1997). Thus the effects of $Q_{A}$ reduction/oxidation and NPQ induction/reversal are allowed to reach completion for the light environment applied. Once this has been achieved the saturating pulse is applied to determine the rise in fluorescence yield to $\mathrm{F}_{\mathrm{m}}$ ' and hence calculation of $\Delta \mathrm{F} / \mathrm{F}_{\mathrm{m}}$ '. SS light curves are often considered to be a measurement of the potential photophysiology of the cells at the time of measurement, as opposed to their actual operational photophysiology at that time. Hence, they reflect the capacity for photosynthesis and for this reason allow comparison between SS light curves of different species and under different environmental conditions. SS light curves can thus be used for examination of phenotypic and genotypic adaptation. For example, the effects of light dose history prior to the light curve are greatly changed, or possibly negated, due to the photoacclimation during each step of the light curve. Obviously some aspects of prior photoacclimation will remain, such as changes in 
pigment bed which take longer to be modified by the cells. In fact the time to reach steady state is a function of light history, e.g. the rate and magnitude of NPQ induction / reversal is a function of previous light dose history. This time period is therefore highly variable, and can be in the order of several minutes or longer. This has several drawbacks when applied to benthic biofilms:-

1. The long duration of the light curves (up to 40 minutes for an 8 step light curve $^{1}$ ) often makes replication of measurements impossible.

2. Investigation of temporal or spatial variation is prohibited by the long time period spent obtaining a single set of measurements.

3. Changes in biofilm surface community may occur over this period of time due to microcycling (e.g. Kromkamp et al. 1998) and positive or negative phototaxis (e.g. Serôdio et al. 2006) induced by the applied PAR, as well as possible diel and tidal patterns in vertical migration (see elsewhere in this chapter), hence measurements at incremental light steps may be made on different cells.

As a result, SS light curves are usually only used with benthic biofilms to determine light parameters in theoretical investigations, rather than in determination of absolute values of light curve parameters. However even in these situations the issue mentioned in Point 4 above can make the light curve largely uninformative, or at least difficult to interpret due to the rapid changes in community structure between light steps. Perkins et al. (2002) demonstrated the complete change in surface community in a benthic biofilm using high resolution fluorescence imaging (HRFI) in an 8 minute light curve, changes being observed in surface diatom taxa and finally a complete

\footnotetext{
${ }^{1}$ Walz fluorometers such as the Diving-PAM and Water-PAM are programmed to have 8 step light curves. However other manufacturer's fluorometers differ and can allow the number of steps to be dictated by the user.
} 
change to a Euglena spp. dominated surface biofilm (Fig. 6.1). As a result SS light curves are often limited to work using cultures of cells or engineered biofilms; in both case migration is inhibited, or preferably prevented (e.g. Jesus et al. 2005; Perkins et al. 2006; Mouget et al. 2008).

\subsection{Rapid Light Curves}

The definition of a RLC is somewhat difficult: when does a light curve become "rapid"? For example Kromkamp et al. (1998) used light curves that were not SS curves, but had light steps of 2 minute duration. This followed on from the first "rapid" light curve work by Schreiber et al. (1994) and Schreiber et al. (1997), the former using 5 minute steps, the latter using truly rapid light curves of 10 seconds. It is the opinion of the authors that to be a true RLC, light steps should be of less than 60 s duration. Using this definition, RLCs were not applied to benthic biofilms until the work of Serôdio et al. (2005), with work on seagrass reviewing the use of RLCs by Ralph and Gademann (2005) in the same year. The methodology was further investigated using benthic diatom cultures and microphytobenthos suspensions (Perkins et al. 2006, Serôdio et al. 2006, Herlory et al. 2007, Cruz and Serôdio 2008) and is now an accepted method for field and laboratory measurements of operational photophysiological state.

In some cases RLCs can be considered to be a compromise between SS light curves and practical limitations of data acquisition and replication. This however is an error as RLCs measure an entirely different photophysiological state, namely the operational photophysiology at that time. The duration of light steps used is often a compromise between practical time limitations and obtaining the required measurements. The longer the duration of each light step, obviously the longer the 
cells exposed to this new PAR will have to photoacclimate and the measurement becomes an intermediate between a RLC and a SS light curve. Indeed many workers now prefer RLCs between 10 and $30 \mathrm{~s}$ at each light step, with $60 \mathrm{~s}$ considered too long due to effects of photoacclimation during the light curve. Also an important consideration, as discussed above, is that the longer each light step, the longer the cells will have to migrate in response to the applied PAR or as part of diel and tidal patterns of vertical migration, hence altering the community structure being investigated during the light response curve itself.

Typically RLCs are of 10,20 or $30 \mathrm{~s}$ at each light step and often have 8 incremental steps ${ }^{1}$ after an initial measurement in darkness (dark adaptation prior to the light curve is discussed below). Thus RLCs may be as short as 80 to $240 \mathrm{~s}$. However migration and photoacclimation will still occur to some extent, with cells migrating vertically at speeds such as $0.17-0.28 \mu \mathrm{m} \mathrm{s}^{-1}$ (Consalvey et al. 2004). Serôdio et al. (1997) estimated the effective measurement depth using fluorescence to be $270 \mu \mathrm{m}$ and Kromkamp et al. (1998) estimated detectable fluorescence measurements from only $150 \mu \mathrm{m}$ sediment depth. Both these estimates are well within the depths to which benthic diatoms migrate, demonstrating the ability of the surface community under investigation to change over even a RLC. Furthermore, Perkins et al. (2006) reported detectable photoacclimation by cultures of benthic diatoms in RLCs with light steps of 10,30 and $60 \mathrm{~s}$ duration. In this case the level of photoacclimation increased as a function of the increase in light step duration, especially for light curves with incremental increases in, as opposed to decreases in, PAR (Fig. 6.2). They further concluded that RLCs with decreasing PAR light steps were preferable to minimise this effect and that light steps of 20 to $30 \mathrm{~s}$ duration were preferable. However if samples have been dark adapted prior to the light curve, then back 
pressure on the electron transport chain due to the time required to reactivate dark reactions, e.g. RUBISCO activation, could result in under estimation of $\Delta \mathrm{F} / \mathrm{F}_{\mathrm{m}}$. It should also be noted that decreasing light steps are not appropriate for SS light curves in which reversal of NPQ is required.

Perkins et al. (2006) indicated that $10 \mathrm{~s}$ was not thought to be an acceptable duration due to limitations of measurements by the flourimeter used (Walz DivingPAM control unit). When cells had been exposed to high light, their rapid induction of NPQ to quench the fluorescence yield after the incremental increase in PAR was such that there was a considerable change in operational fluorescence yield $(F)$ between measurement of $\mathrm{F}$ and application of the saturating pulse and subsequent measurement of $F_{m}$ '. Where this happened, $F_{m}$ ' was under estimated relative to $F$ causing under estimation of $\Delta \mathrm{F} / \mathrm{F}_{\mathrm{m}}$ ' and hence the calculated value of ETR.

While this question demands for further research, it is clear that the most appropriated light step to be used in each case will depend on the relative benefit of avoiding the mentioned artefact when applying $10 \mathrm{~s}$, and of the confounding errors introduced by increasing the light step to 20 s, namely short-term photoacclimation and migratory responses during the construction of the light curve. For example, the detection of diel rhythms in the photoacclimation status of microphytobenthos using RLCs has been shown to be possible when applying short light steps of 10 or $20 \mathrm{~s}$, whilst becoming almost undetectable when using light steps of $40 \mathrm{~s}$ due to the rapid light-activation of dark-acclimated samples (Serôdio et al. 2005).

Despite the mentioned potential problems, incremental RLCs using $10 \mathrm{~s}$ light steps were shown to allow to characterise the steady-state photoacclimation status of samples acclimated to a wide range of ambient irradiances, through the estimation of the light-saturation parameter $E_{k}$ from RLC parameters (Serôdio et al. 2006, Cruz and 
Serôdio 2008). These studies have also demonstrated that such short RLCs could effectively 'capture' the steady-state photoacclimation status formed prior to the RLC. RLC parameters responded to ambient irradiance (Fig. 6.3) in a well-defined way, with the initial slope of RLCs decreasing with ambient irradiance (related to the buildup of NPQ; see section on XC), and maximum ETR increasing with ambient irradiance. As a consequence, RLCs could be related to steady-state light curve parameters, with significant correlations being found between the initial slopes of both light curves for samples acclimated to lower ambient irradiances, and between the maximum ETR of both curves for samples acclimated to higher ambient irradiances (Serôdio et al. 2006).

In their application to benthic biofilms, RLCs have distinct benefits over traditional SS light curves. They minimise changes in community structure due to migration, as well as reducing methodologically induced photoacclimation to modify the photoacclimation state of the cells under investigation. However the authors suggest that care needs to be taken in their interpretation as they are comparative measurements that should only be compared between studies using the same methodologies. Data are only comparable so long as the duration of the incremental light steps used are the same. It should also be noted that the magnitude of light level used for each light step will also result in variation between studies; photoacclimation will be proportional to the total light dose experienced during the light curve and measurements with higher light levels will induce more photoacclimation over the duration of the light curve.

It is worth mentioning at this point the issue of dark adaptation prior to the light curve itself. In many studies light curves are preceded by a short period of dark adaptation. This is usually to obtain an approximate measurement of the maximum 
fluorescence yield $F_{m}$ for calculation of parameters such as NPQ (where NPQ $=\left(F_{m^{-}}\right.$ $\left.F_{m}{ }^{\prime}\right) / F_{m}$ ', see elsewhere in this chapter). However it can also be argued that such dark acclimation modifies the photoacclimation state of the cells investigated and, if of sufficient duration, dark acclimation can induce vertical migration (Jesus et al., 2006). However work by Kromkamp et al. (unpublished) indicated that a dark adaptation period of 1 minute prior to the light curve did not affect the RLC data obtained in a series of light curves logged over an emersion period. It is probable that the effect of the dark period is proportional to the photoacclimation state of the cells, and hence on the photodose (light history effect) experienced by the cells, as well as the propensity for the cells to migrate as a function of changes in light environment. It is suggested that, to standardise methodologies and hence increase comparative capability, dark adaptation should be avoided prior to light curves. Comparative values of $F_{m}$ and hence calculation of parameters such as NPQ may still be achieved as in most cases fluorometer programming results in the first light curve steps being in darkness and at low light. The former replaces the dark adapted measurement, and Jesus et al. (2006) indicated that, for benthic diatoms which retain NPQ in the dark, low light reverses NPQ more efficiently than darkness, hence giving a value of $F_{m}$ ' which exceeds $F_{m}$ in

some instances (see elsewhere in this chapter). However, as with most methodologies, the use of dark adaptation will depend on what is being investigated, and in some studies reversal of NPQ prior to the light curve may be required.

\subsection{Non-sequential Light Curves}

The last form of light curve to be discussed here are NSLCs, in which each light step is applied to a separate culture sample or biofilm sample/area that has not been used for any previous measurements as part of the light curve (Perkins et al. 
2006, Herlory et al. 2007). For example, the fluorometer probe is placed over one (sub)sample for the selected light step duration, at the end of which $\Delta \mathrm{F} / \mathrm{Fm}$ ' is obtained. The probe is then moved to the next (sub)sample for the next light step of the light curve. There is no requirement here for the measurements to be sequential, but for this methodology dark adaptation prior to the light curve is not possible. In most cases this is a theoretical light curve as it requires an extensive set of replicate samples (e.g. cultures) or, in the case of field measurements, a substantially large area of biofilm which is considered to be homogeneous enough to allow a large number of replicate measurements. This method should therefore almost totally remove the photoacclimation induced by the light curve and, with enough replication, can be considered to be measuring the true operational photoacclimation state of the cells. The disadvantage is the number of replicates required.

Perkins et al. (2006) applied this method to cultures of benthic diatom cells, principally the species Navicula phyllepta. Despite using different culture sub samples for each light step, photoacclimation still occurred, with $\mathrm{rETR}_{\max }$ proportional to the increasing length of each light step. Notable however was that down regulation was observed at irradiances above the point where the curve saturated when light steps were of short duration (e.g. 10 and 30 s), and also that steady state light curves did not saturate at all and showed the highest $\mathrm{rETR}_{\max }$ values (Fig. 6.4). This demonstrates the rapid rate of induction of photoacclimation processes during the light curve steps themselves. Also reported by Perkins et al (2006) was the effect of light history, when cultures incubated at high light level $\left(400 \mu \mathrm{mol} \mathrm{m} \mathrm{s}^{-2} \mathrm{PAR}\right)$ prior to the light curve measurements did not saturate or show down regulation, but cultures incubated at low light $\left(25 \mu \mathrm{mol} \mathrm{m} \mathrm{m}^{-2} \mathrm{~s}^{-1} \mathrm{PAR}\right)$ showed both saturation and down regulation for 10 and $30 \mathrm{~s}$ light curves, saturation for $60 \mathrm{~s}$ curves, but no saturation for steady state curves. 
The rate and level of photoacclimation processes was therefore proportional to light history and the length of the light curve steps used. An important point that should be mentioned at this point is that the light curves referred to in Perkins et al. (2006) used rETR. It would be expected that as photoacclimation increased, a higher level of NPQ induction would result in a lower effective ETR. Thus if the cross section of PSII had been measured to determine the "true" ETR as opposed to rETR, the ETR $\mathrm{Eax}_{\operatorname{may}}$ decrease as a function of increasing light step duration. This clearly needs further investigation, although the measurement of PSII cross section is difficult for benthic biofilms during light curves.

\subsection{Light Curves Summary}

The use of steady state light curves has been a powerful tool in the use of fluorescence to investigate photophysiology of photoautotrophs, but due to the long duration required for measurement to be achieved is not practical for the use with benthic biofilms, especially those exhibiting rapid migratory activity in response to changes in light environment or as part of diel and tidal rhythms. It is suggested here that RLCs of 10-30 s duration with no prior dark adaptation step should be utilised, the particular light step to be applied being dependent on the previous evaluation of the relative magnitude of the errors introduced by (i) photoacclimation and (ii) migration during the RLC, and (iii) fluorometer software, factors varying with sample composition and light history, light levels applied during the RLC, and instrument characteristics. Furthermore, RLCs starting at high light and proceed to lower irradiance may represent a advantageous alternative to minimize the effect of cumulative light dose on the PSII quantum efficiency, although systematic comparative studies are still missing. Having said this, this would require a change in 
the setup of the automated LC used to be made with Walz-PAM fluorometers, as currently the models mostly used in the field (minPAM, divingPAM) can only make LC from low to high light. Obviously this does not rule out further work in which different durations of light step are used to investigate photoacclimation etc., indeed this is highly recommended by the authors, especially with regard to the use of RLCs in situ.

\section{Comparison of fluorescence with other methodologies}

In section 5 we described how absolute rates of electron transport can be calculated. However, ETR is not the common currency in primary production studies. Photosynthetic rate measurements in aquatic organisms usually imply recording of either $\mathrm{O}_{2}$ emission (e.g., oxymetry, mass spectrometry) or $\mathrm{CO}_{2} / \mathrm{HCO}_{3}{ }^{-}$uptake (e.g., ${ }^{14} \mathrm{C}$ labelling, infra-red gas analysis) and in the marine environment as well as in ecosystem models $\mathrm{C}$ is the most often used. A comparison between ETR and the rate of oxygen evolution or C-fixation $\left(\mathrm{P}^{\mathrm{B}}\right)$ can be obtained from a comparison of both methods: when $\mathrm{P}^{\mathrm{B}}$ is plotted as a function of ETR the regression coefficient (provided a linear relationship is obtained) is the conversion factor needed to convert ETR into $\mathrm{P}^{\mathrm{B}}$ and thus equals the efficiency electron yield $\left(\Phi_{\mathrm{e}}\right)$ for $\mathrm{O}_{2}$ evolution or C-fixation (mol $\mathrm{O}_{2}$ produced or $\mathrm{CO}_{2}$ fixed per mol electron produced. Thus:

$$
\mathrm{P}^{\mathrm{B}}=\Phi_{\mathrm{e}} \cdot \mathrm{ETR}
$$

Theoretically the optimal value for $\Phi_{\mathrm{e}}$ is 0.25 , which means that in the case of $\mathrm{O}_{2^{-}}$ evolution 4 absorbed photons give rise to 4 charge separations and thus the production of 4 electrons. In the case of C-fixation we need to know the photosynthetic quotient (PQ) if we like to convert rates of $\mathrm{O}_{2}$-evolution to rates of C-fixation. Thus:

$$
\mathrm{P}^{\mathrm{B}}\left(\mu \mathrm{mol} \mathrm{O}{ }_{2}(\mathrm{mg} \operatorname{chl} a)^{-1} \mathrm{~s}^{-1}\right)=\Phi_{\mathrm{e}} \cdot \mathrm{ETR}
$$




$$
\mathrm{P}^{\mathrm{B}}\left(\mu \mathrm{mol} \mathrm{C}(\mathrm{mg} \operatorname{chl} a)^{-1} \mathrm{~s}^{-1}\right)=\Phi_{\mathrm{e}} \cdot \mathrm{ETR} \cdot \mathrm{PQ}^{-1}
$$

As explained above, two different methods to active fluorescence have been developed: the Pulse Amplitude Modulated (PAM) principle which uses a MT-flash to measure $\mathrm{F}_{\mathrm{m}}$ and the Fast Repetition rate Fluorometry (FRRF) ${ }^{2}$. It should be noted that when the MT method is used (eq. 1, 3) with a fluorometer giving a ST-flash, the $\mathrm{F}_{\mathrm{m}}\left(\mathrm{F}_{\mathrm{m}-\mathrm{ST}}\right)$ measured is lower than that measured with a MT-flash $\left(\mathrm{F}_{\mathrm{m}-\mathrm{MT}}\right)$. As a consequence a lower PSII efficiency is obtained and thus a lower rate of ETR, because a ST flash leads to a single reduction of all $\mathrm{Q}_{\mathrm{A}}$, whereas an MT flash also reduces the $\mathrm{Q}_{\mathrm{B}}$ and PQ-pool, leading to a higher $\mathrm{F}_{\mathrm{m}}$ (Schreiber et al. 1995, Koblizek et al. 2001, Suggett et al. 2003, Kromkamp and Forster, 2003). ETR measured using a PAM fluorometer can be up to ca. $35 \%$ higher than ETR measured using a FRRF (Suggett et al. 2003, Kromkamp and Forster 2003).

At room temperature, most of the fluorescence emission originates from PSII and because charge separation and the splitting of water in the oxygen evolving complex both take place in RCII it might be expected that ETR and the rate of gross $\mathrm{O}_{2}$-evolution show a tight coupling. As carbon fixation (the "dark reactions") takes place 'later' and is a 'more distant' step of the photosynthetic process, a more loose relationship might be obtained. Interestingly some diatoms seem also be able to use a C4-like C-fixation process using phosphoenolpyruvate carboxykinase (PEPCKase) or phosphoenolpyruvate carboxylase (PEPCase) (Cabello-Pasini et al. 2001, McGinn and Morel 2008) but whether MPB diatoms also possess this capacity has not been investigated yet.

Table 2 presents a compilation of studies where rates of ETR are compared to rates of photosynthesis obtained using more classical methods. Only a small number

\footnotetext{
${ }^{2}$ Several manufacturers make PAM-like fluorometers (e.g. Walz, PSI, Hansatech, Moldaenke). Fluorometers using the ST-protocol are made by Chelsea Instruments, Satlantic, PSI (and some Walz models). The former 2 use the FRRF protocol and can apply MT and ST flashes.
} 
$(12 \%)$ of these studies deal with biofilms. Most of these studies (85\%) concern marine organisms, and $c a .70 \%$ relate to field studies or use natural samples photoacclimated in the laboratory for different periods of time. Natural phytoplankton studies mainly used the ST-approach; 5 studies used the 'pump and probe' and 18 used the FRRF techniques (mostly Chelsea's FAST ${ }^{\text {tracka }}$ ), whereas only 6 studies used a PAM-type fluorometer in natural systems. The MT-PAM fluorometer is the apparent method of choice for seagrasses and macroalgal studies (16 out of 16) and both types are used for culture studies of unicellular algae. Fluorescence estimates of photosynthesis (from which ca. 20\% are expressed as rETR, see 4 above) have been compared mainly with oxygen-evolution data (39 out of 66 references, including all the macroalgal/seagrass studies), and 4 dealing with ${ }^{18} \mathrm{O}_{2}$ and ${ }^{17} \mathrm{O}_{2}$ ). In 27 out of the 67 references cited in Table 2 fluorescence was compared to a ${ }^{14} \mathrm{C}$-based method, the majority reporting on phytoplankton productivity. A limited number (6) compared ETR to both oxygen evolution and carbon fixation. $35 \%$ of the studies combined the different photosynthesis measurements simultaneously on the same sample, and 11 out of the 67 studies ran experiments in parallel (same time, but on different subsamples).

A global survey of Table 2 shows that in more than $75 \%$ of the studies cited, a good correlation was observed between rETR and other methods to estimate photosynthesis. Usually fluorescence methods gave higher estimates of photosynthesis, i.e., the value of $\Phi_{\mathrm{e}}$ and/or PQ was overestimated (eq. 7). The PQ value depends on the $\mathrm{N}$-source for growth and is close to 1 when ammonia is the sole nitrogen source and 1.3 when nitrate is the N-source for growth (Williams 1993). This is because the reduction of nitrate requires photosynthetically produced electrons. Many studies, however, show a large variation in PQ, which is at least partly due to 
methodological errors (Williams and Robertson 1991). Another reason for the overestimate of C-fixation by ETR is that often an a priori assumption is made of $\Phi_{\mathrm{e}}$, which is assumed to equal 0.25 (= 1 mol oxygen per 4 mol photons absorbed). However, culture work shows that this optimal value is often not reached, and that it is closer to 6-7 mol oxygen per 4 mol photons absorbed (Flameling and Kromkamp 1998). For this reason Raateoja et al. (2004) used a value of 0.18 for $\Phi_{\mathrm{e}}$ and assuming a PQ of 1.5 , Kromkamp et al (in press) calculated that $\Phi_{\mathrm{e}}$ equalled 0.15 . Another reason for an overestimation might be that the chosen value for $n_{\text {PSII }}$ when using the ST-method might be overestimated. This is discussed above in section 5 on rETR vs ETR.

MPB hardly features in the table (12\%) and no direct estimates of C-fixation are made using a-priori assumptions for $\Phi_{\mathrm{e}}$. This is because the optical conditions in the MPB are so complex that absolute estimates of ETR are very difficult to make, related to the fact that quantification of rETR is hindered by difficulties in measuring the absorption coefficient of MPB, the presence of vertical migration in muddy sediments and the artefacts caused by deep layer fluorescence. These issues are discussed in the section on rETR vs ETR. To circumvent this problem several approaches have been tried: Barranguet and Kromkamp (2000) measured rETR at the sediment surface and compared the photosynthetic parameters obtained from those with those obtained from ${ }^{14} \mathrm{C}$-fixation made on sediment slurries. Assuming no vertical migration and a homogenous chl a distribution with depth they calculated a conversion factor (called EE) and estimated depth integrated primary production. Their results demonstrated that with the assumptions mentioned, a single conversion factor could be used to estimate primary production throughout the year at different stations. At high light non-linearity was often observed, which could be due to 
physiological factors (see below) but which could also be due to deep layer fluorescence, although that was not realized by the authors at the time. The EE factor calculated by Barranguet and Kromkamp (2000) corresponded with the conversion factor obtained from a culture study with the benthic diatom Cylindrotheca closterium (Morris and Kromkamp, 2003). Because the approach taken by Barranguet and Kromkamp (2000) did not take different vertical biomass distribution profiles in consideration. Serôdio (2003) developed a chlorophyll fluorescence based index to estimate photosynthesis:

$$
P_{f \text { fuo }}=E \frac{F_{o}}{F_{o, s e d}} \Delta F / F_{m}^{\prime}
$$

Basically this equation approximates to:-

$$
\mathrm{P}_{\text {fluo }}=\mathrm{F}_{\mathrm{o}} \cdot \mathrm{rETR}
$$

where $F_{o}$ in eq. $8 \mathrm{a}$ is corrected for background fluorescence of the sediment (and which should always be done as well as possible). The rationale of this approach is that $\mathrm{F}_{\mathrm{o}}$ is a good proxy for the [chl a] in the photic zone of the sediment, and thus reflects the vertical biomass profile. The author compared the photosynthesis estimates of the fluorescence index with those obtained from microelectrode mechanisms (gross oxygen production using the light dark shift technique, Revsbech and Jørgensen, 1983) and found in general a linear relationship between both methods and the slopes did not differ significantly, suggesting that this index might be a powerful method to estimate MPB primary production. The validity of this model was corroborated using a model by Forster and Kromkamp (2004) (Fig. 7.1) who showed that the slope between the modelled and measured production depended little on the shape of the vertical biomass profile of the MPB. Recently Serôdio et al. (2007) confirmed the validity of the model results by demonstrating a linear relationship 
between the fluorescence index shown in eq. $8 \mathrm{a}$ and measurements obtained using oxygen microelectrodes. As in the model study by Forster and Kromkamp (2004), and also demonstrated in a laboratory study with light and temperature treatments simulating seasons (Lefebvre et al. 2007), the slope of the regression between both methods varied throughout the year (Fig. 7.2), thus requiring a regular calibration of the conversion factor. If we consider only the studies for which the measurements were made simultaneously, in all but two studies (Flameling and Kromkamp, 1998; Hanelt and Nultsch, 1995), was the relation between fluorescence-based and oxygenbased estimates of photosynthesis linear. In most cases, ETR closely matched oxygenor carbon-based estimates of photosynthesis.

On the other hand, in less than $25 \%$ of the references cited, a non linear, or a weak relation was observed. Usually, the non-linearity between $\mathrm{P}^{\mathrm{B}}$ and ETR was observed at high irradiances above $\mathrm{E}_{\mathrm{k}}$. This is a general pattern, independent of the taxonomic level, as it can be observed in seagrasses, macroalgae, microalgae and in cyanobacteria. This non-linearity where ETR became relatively higher than $\mathrm{P}^{\mathrm{B}}$ was attributed to light dependent $\mathrm{O}_{2}$ consuming processes (photorespiration, chlororespiration, mitochondrial respiration in light, Mehler reaction (Flameling and Kromkamp 1998)) or other alternative electron sinks (e.g. thioredoxin, nitrogen reduction, Lomas and Glibert 1999), alternative electron pathways (cyclic transport around PSII and/or PSI, Lavaud et al. 2002), transfer of reductants from chloroplasts to mitochondria (OAA-malate and DHAP-PGA shuttles, Behrenfeld et al. 2004), different time-scale between fluorescence- and oxygen- or carbon-based measurements, methodological constraints in determination of the fraction of light absorbed by PSII (especially in biofilms, see section on rETR vs ETR), difference in apparatus sensitivity, vertical migration and contribution of subsurface cells in the 
case of MPB. Moreover, non-linearity could be also light dependent, varying according to the light level experienced by the cells or to their light history, which in turn greatly influences the light absorption (or utilization) characteristics needed to estimate ETR.

Thus, in spite of an increasing number of studies dedicated to study the variation of photosynthetic parameters in microalgae using fluorometry and to compare them with other methods, many uncertainties still remain. This calls for a more in depth study of how the different parameters needed to calculate absolute ETR (a* ${ }^{*}$ PSII,$\left.n_{\text {PSII }}\right)$ and convert these to rates of $\mathrm{C}$-fixation $\left(\Phi_{\mathrm{e}}, \mathrm{PQ}\right)$ vary and depend on nutrient status, light histories and growth rate (e.g., see discussion in Morris and Kromkamp (2003), and this applies especially to organisms producing biofilms, with their specific constraints.

\section{General summary}

The application of variable chlorophyll fluorescence to microphytobenthic (MPB) biofilms in soft sediment systems is complex as a result of the signal emanating form subsurface cells, cellular vertical migration within the sediment matrix, a high capacity for down regulation, chlororespiration in the dark and the effects of the physical structure of the sediment/biofilm matrix (light attenuation by the sediment matrix) itself. Despite these factors, fluorescence has yielded a large and valuable range of information on the ecology, physiology and productivity of MPB biofilms and indeed at the species level of diatoms, cyanobacteria and other taxa comprising them. Care in design of methods, including timing measurements away from periods of maximal migration and minimising measurement duration, as well as the use of numerical simulations to deconvolute depth-integrated measurements 
(Serôdio 2004) have enabled correct interpretation of data, enhancing our knowledge of biofilm functioning and (photo)physiology. Fluorescence has provided valuable information on down regulatory measurements including xanthophyll cycling in the form of non photochemical quenching and PS II electron cycling (Perkins et al. 2006, Serôdio et al. 2005, 2006, Herlory et al. 2007, Lavaud et al. 2007, Cruz and Serôdio 2008). We now have a far better understanding of the use of fluorescence as a biomass proxy (Honeywill et al. 2002, Jesus et al. 2006), in the calculation of ETR and the construction of light response curves (Perkins et al. 2006, Serôdio et al. 2006, Herlory et al. 2007, Cruz and Serôdio 2008) and particularly encouraging is the correlation between fluorescence methodology and alternative methods such as oxymetry and carbon uptake (Table 1) for measurement of productivity (Barranguet and Kromkamp 2000, Forster and Kromkamp 2004, Kromkamp and Forster 2003, Morris and Kromkamp 2003, Morris et al. 2008, Serôdio et al. 2005, 2006, 2007). The application of fluorimetry to the MPB is still comparatively at an early stage and there is much more to be done to investigate the complex photophysiology of the species comprising the biofilms as well as in developing applied outputs of models of productivity and other ecosystem functions of these important ecosystems. 


\section{References}

Admiraal W (1984) The ecology of estuarine sediment inhabiting diatoms. In : Progress in Phycological Research. Eds Round F.E. and Chapman D.J. Vol. 3 : 269-322. Biopress Limited, Bristol.

Babin M, Morel A, Claustre H, Bricaud A, Kolber Z, Falkowski PG (1996) Nitrogenand irradiance-dependent variations of the maximum quantum yield of carbon fixation in eutrophic, mesotrophic and oligotrophic marine systems. Deep-Sea Research Part I-Oceanographic Research Papers 43, 1241-1272.

Barranguet C, Kromkamp J (2000) Estimating primary production rates from photosynthetic electron transport in estuarine microphytobenthos. Marine Ecology-Progress Series 204:39-52

Beer S, Bjork M (2000) Measuring rates of photosynthesis of two tropical seagrasses by pulse amplitude modulated (PAM) fluorometry. Aquatic Botany 66, 69-76.

Beer S, Axelsson L (2004) Limitation in the use of PAM fluorometry for measuring photosynthtic rates of macroalgae at high irradiances. Eur. J. Phycol. 39, 1-7.

Beer S, Larson C, Poryan O, Axelsson L (2000) Photosynthetic rates of Ulva lactuca (Chlorophyta) measured by pulse amplitude modulated (PAM) fluorometry. Eur. J. Phycol. 35, 69-74.

Beer S, Vilenkin B, Weil A, Veste M, Susel L, Eshel A (1998) Measuring photosynthetic rates in seagrasses by pulse amplitude modulated (PAM) fluorometry. Marine Ecology-Progress Series 174:293-300

Berner T, Dubinsky Z, Wyman K, Falskowski PG (1989) Photoadaptation and the "package" effect in Dunaliella tertiolecta (Chlorophyceae). Journal of Phycology 25:70-78 
Behrenfeld, M.J., Prasil, O., Babin, M., Bruyant, F., 2004. In search of physiological basis for covariations in light-limited and light-saturated photosynthesis. J. Phycol. 40, 4-25.

Bidigare RR (1990) In vivo absorption properties of algal pigments. In: SPIE Ocean Optics X, pp 290-302

Boyd, P.W., Aiken, J., Kolber, Z., 1997. Comparison of radiocarbon and fluorescence based (pump and probe) measurements of phytoplankton photosynthetic characteristics in the Northeast Atlantic Ocean. Mar. Ecol. Prog. Ser. 149, 215-226.

Bradbury M, Baker NR (1981) Analysis of the Slow Phases of the In vivo Chlorophyll Fluorescence Induction Curve - Changes in the Redox State of Photosystem-Ii Electron-Acceptors and Fluorescence Emission from Photosystem-I and Photosystem-II. Biochimica and Biophysica Acta 635:542551

Buchanan BB, Balmer Y (2005) Redox regulation: a broadening horizon. Annu. Rev. Plant Biol. 56: 187-220

Cabello-Pasini, A., Figueroa, F.L., 2005. Effect of nitrate concentration on the relationship between photosynthetic oxygen evolution and electron transport rate in Ulva rigida (Chlorophyta). Journal of Phycology 41, 1169-1177.

Cabello-Pasini A, Swift H, Smith GJ, Alberte RS (2001) Phosphoenolpyruvate carboxykinase from the marine diatom Skeletonema costatum and the phaeophyte Laminaria setchellii. II. Immunological characterization and subcellular localization. Bot Mar 44:199-207

Carr, H., Bjork, M., 2003. A methodological comparison of photosynthetic oxygen evolution and estimated electron transport rate in tropical Ulva 
(Chlorophyceae) species under different light and inorganic carbon conditions. Journal of Phycology 39, 1125-1131.

Carr, H., Bjork, M., 2007. Parallel changes in non-photochemical quenching properties, photosynthesis and D1 levels at sudden, prolonged irradiance exposures in Ulva fasciata Delile. Journal Of Photochemistry And Photobiology B-Biology 87, 18-26.

Consalvey MC, Jesus B, Perkins RG, Brotas V, Underwood GJC, Paterson DM (2004) Monitoring migration and measuring biomass in benthic biofilms: the effects of dark/far-red adaptation and vertical migration on fluorescence measurements. Photosynth. Res. 81: 91-101.

Corno, G., Letelier, R.M., AZbbott, M.R., Karl, D.M., 2005. Assessing primary production variability in the North Pacific subtropical gyre: a comparison of Fast Repetition Fate Fluorometry and 14C measurements. Journal of Phycology 42, 51-60.

Cruz S, Serôdio J (2008) Relationship of rapid light curves of variable fluorescence to photoacclimation and non-photochemical quenching in a benthic diatom. Aquat. Bot. 88: 256-264.

Dijkman NA, Kroon BMA (2002) Indications for chlororespiration in relation to light regime in the marine diatom Thalassiosira weissflogii. J. Photochem. Photobiol. B 66: 179-187.

Domin, A., Forster, R.M., Hintze, R., Kohler, J., 1998. Comparison of different types of chlorophyll fluorometers. Rostock. Meeresbiol. Beitr. 6, 81-92.

Dubinsky Z, Falkowski PG, Wyman K (1986) Light harvesting and utilization by phytoplankton. Plant Cell Physiology 27:1335-1349 
Estevez-Blanco, P., Cermeno, P., Espineira, M., Fernandez, E., 2006. Phytoplankton photosynthetic efficiency and primary production rates estimated from fast repetition rate fluorometry at coastal embayments affected by upwelling (Rias Baixas, NW of Spain). Journal Of Plankton Research 28, 1153-1165.

Falkowski PG (1981) Light-shade adaptation and assimilation numbers. JournalofPlanktonResearch 3:203-216

Falkowski PG, Owens TG, Ley AC, Mauzerall DC (1981) Effects of growth irradiance levels on the ratio of reaction centers in two species of marine phytoplankton. Plant Physiology 68:969-973

Falkowski, P.G., Fujita, Y., Ley, A., Mauzerall, D., 1986a. Evidence For Cyclic Electron Flow Around Photosystem-Ii In Chlorella-Pyrenoidosa. Plant Physiology 81, 310-312.

Falkowski PG, Wyman K, Ley AC, Mauzerall DC (1986) Relationship of steady-state photosynthesis to fluorescence in eucaryotic algae. BiochimicaetBiophysicaActa 849:183-192

Falkowski, P.G., Ziemann, D., Kolber, Z., Bienfang, P.K., 1991. Role Of Eddy Pumping In Enhancing Primary Production In The Ocean. Nature 352, 55-58.

Flameling IA, Kromkamp J (1998) Light dependence of quantum yields for PSII charge separation and oxygen evolution in eucaryotic algae. Limnol Oceanogr $43: 284-297$

Forster RM, Kromkamp JC (2004) Modelling the effects of chlorophyll fluorescence from subsurface layers on photosynthetic efficiency measurement in microphytobenthic algae. Marine Ecology-Progress Series 284:9-22 
Franklin, A.L., Badger, M.R., 2001. A comparison of photosynthetic electron transport rates in macroalgae measured by pulse amplitude modulated chlorophyll fluorometry and mass spectrometry. J. Phycol. 37, 756-767.

Fujiki, T., Suzue, T., Kimoto, H., Saino, T., 2007. Photosynthetic electron transport in Dunaliella tertiolecta (Chlorophyceae) measured by fast repetition rate fluorometry: relation to carbon assimilation. Journal Of Plankton Research 29, 199-208.

Fujiki, T., Hosaka, T., Kimoto, H., Ishimaru, T., Saino, T., 2008. In situ observation of phytoplankton productivity by an underwater profiling buoy system: use of fast repetition rate fluorometry. Marine Ecology-Progress Series 353, 81-88.

Geel, C., Versluis, W., Snel, J.F.H., 1997. Estimation of oxygen evolution by marine phytoplankton from measurement of the efficiency of photosystem II electron flow. Photosynth. Res. 51, 61-70.

Gilbert, M., Wilhelm, C., Richter, M., 2000a. Bio-optical modelling of oxygen evolution using in vivo fluorescence: Comparison of measured and calculated photosynthesis/irradiance (P-I) curves in four representative phytoplankton species. J. Plant Physiol. 157, 307-314.

Gilbert, M., Domin, A., Becker, A., Wilhelm, C., 2000b. Estimation of primary productivity by chlorophyll a in vivo fluorescence in freshwater phytoplankton. Photosynthetica 38, 111-126.

Glud, R.N., Rysgaard, S., Kuhl, M., 2002. A laboratory study on O-2 dynamics and photosynthesis in ice algal communities: quantification by microsensors, $\mathrm{O}-2$ exchange rates, C-14 incubations and a PAM fluorometer. Aquatic Microbial Ecology 27, 301-311. 
Goss RE, Pinto A, Wilhelm C, Richter M (2006) The importance of a highly active and delta-pH-regulated diatoxanthin epoxidase for the regulation of the PS II antenna function in diadinoxanthin cycle containing algae. J. Plant Physiol. 163: $1008-1021$

Hader, D.P., Herrmann, H., Schafer, J., Santas, R., 1997. Photosynthetic fluorescence induction and oxygen production in two Mediterranean Cladophora species measured on site. Aquatic Botany 56, 253-264.

Hancke, K., Hancke, T.B., Olsen, L.M., Johnsen, G., Glud, R.N., 2008a. Temperature effects on microalgal photosynthesis-light responses measured by O-2 production, pulse-amplitude-modulated fluorescence, and C-14 assimilation. J. Phycol. 44, 501-514.

Hancke, T.B., Hancke, K., Johnsen, G., Sakshaug, E., 2008b. Rate of O-2 production derived from pulse-amplitude-modulated fluorescence: Testing three biooptical approaches against measured O-2-production rate. Journal Of Phycology 44, 803-813.

Hanelt, D., Nultsch, W., 1995. Field studies of photoinhibition show non-correlations between oxygen and fluorescence measurements in the arctic red alga Palmaria palmata. J. Plant Physiol. 145, 31-38.

Hanelt, D., Uhrmacher, S., Nultsch, W., 1995. The Effect Of Photoinhibition On Photosynthetic Oxygen Production In The Brown Alga Dictyota-Dichotoma. Botanica Acta 108, 99-105.

Hartig, P., Wolfstein, K., Lippemeier, S., Colijn, F., 1998. Photosynthetic activity of natural microphytobenthos populations measured by fluorescence (PAM) and 14C-tracer methods: a comparison. Mar. Ecol. Prog. Ser. 166, 53-62. 
Heinze, I., Dau, H., Senger, H., 1996. The relation between the photochemical yield and variable fluorescence of photosystem II in the green alga Scenedesmus obliquus. Journal Of Photochemistry And Photobiology B-Biology 32, 89-95.

Herlory O, Richard P, Blanchard G (2007) Methodology of light response curves: application of chlorophyll fluorescence to microphytobenthic biofilms. Mar. Biol. 153: 91-101.

Honeywill C, Hagerthey SE, Paterson DM (2002) Determination of microphytobenthic biomass using pulse-amplitude modulated minimum fluorescence. European Journal of Phycology 37: 485-492.

Jakob T, Wilhelm C (2001) Unusual pH-dependence of diadinoxanthin de-epoxidase activation causes chlororespiratory induced accumulation of diatoxanthin in the diatom Phaeodactylum tricornutum. J. Plant Physiol. 158: 383-390.

Jakob T, Goss R, Wilhelm C (1999) Activation of diadinoxanthin de-epoxidase due to a chlororespiratory proton gradient in the dark in the diatom Phaeodactylum tricornutum. Plant Biol. 1: 76-82.

Jesus B, Perkins RG, Mendes CR, Brotas V, Paterson DM (2006a) Chlorophyll fluorescence as a proxy for microphytobenthic biomass: alternatives to the current methodology. Mar. Biol. 150: 17-28.

Jesus B, Perkins RG, Consalvey MC, Brotas V, Paterson DM (2006b) Effects of vertical migration by benthic microalgae on fluorescence measurements of photophysiology. Mar. Ecol. Prog. Ser. 315: 55-66.

Jesus B, Mendes C, Brotas V, Paterson DM (2006c) Effect of sediment type on microphytobenthos vertical distribution: Modelling the productive biomass and improving ground truth measurements. J Exper Mar Biol Ecol 332: 60-74 
Johnsen G, Sakshaug E (2007) Biooptical characteristics of PSII and PSI in 33 species (13 pigment groups) of marine phytoplankton, and the relevance for pulseamplitude-modulated and fast-repetition-rate fluorometry. Journal of Phycology 43:1236-1251

Kaiblinger, C., Dokulil, M.T., 2006. Application of fast repetition rate fluorometry to phytoplankton photosynthetic parameters in freshwaters. Photosynthesis Research 88, 19-30.

Koblizek M, Kaftan D, Nedbal L (2001) On the relationship between the nonphotochemical quenching of the chlorophyll fluorescence and the photosystem II light harvesting efficiency. A repetitive flash fluorescence induction study. Photosynth Res 68:141-152

Koblizek, M., Ciscato, M., Komenda, J., Kopecky, J., Siffel, P., Masojidek, J., 1999. Photoadaptation in the green alga Spongiochloris sp. A three-fluorometer study. Photosynthetica 37, 307-323.

Kolber Z, Falkowski PG (1993) Use of active fluorescence to estimate phytoplankton photosynthesis in situ. Limnology and Oceanography 38:1646-1665

Kolber ZS, Prásil O, Falkowski PG (1998) Measurements of variable chlorophyll fluorescence using fast repetition rate techniques: defining methodology and experimental protocols. Biochimica et Biophysica Acta 1367:88-106

Kramer DM, Johnson G, Kiirats O, Edwards GE (2004) New fluorescence parameters for the determination of $\mathrm{Q}(\mathrm{A})$ redox state and excitation energy fluxes. Photosynthesis Research 79:209-218

Kromkamp J, Barranguet C, Peene J (1998) Determination of microphytobenthos PSII quantum efficiency and photosynthetic activity by means of variable chlorophyll fluorescence. Mar Ecol Progr Ser 162: 45-55 
Kromkamp J, Limbeek M (1993) Effect of short-term variation in irradiance on lightharvesting and photosynthesis of the marine diatom Skeletonema costatum: a laboratory study simulating vertical mixing. Journal of General Microbiology $139: 2277-2284$

Kromkamp JC, Forster RM (2003) The use of variable fluorescence measurements in aquatic ecosystems: differences between multiple and single turnover measuring protocols and suggested terminology. European Journal of Phycology 38:103-112

Kromkamp, J.C., Domin, A., Dubinsky, Z., Lehmann, F., Schanz, F., 2001. Changes in photosynthetic properties measured by oxygen evolution and variable chlorophyll fluorescence in a simulated entrainment experiment with the cyanobacterium Planktothrix rubescens. Aquat. Sci. 63, 363-382.

Kromkamp, J.C.,Dijkman, N.A., Peene, J., Simis, S.G.H., Gons, H.J. 2008. Estimating phytoplankton primary production in Lake IJsselmeer (The Netherlands) using variable fluorescence (PAM-FRRF) and C-uptake techniques. Eur. J. Phycol. (in press).

Kroon, B., Prezelin, B.B., Schofield, O., 1993. Chromatic regulation of quantum yields for photosystem II charge separation, oxygen evolution, and carbon fixation in Heterocapsa pygmaea (Pyrrophyta). J. Phycol. 29, 453-462.

Kroon, B.M.A., 1994. Variability of photosystem II quantum yield and related processes in Chlorella pyrenoidosa (Chlorophyta) acclimated to an oscillating light regime simulating a mixed photic zone. J. Phycol. 30, 841-852.

Kühl, M., Glud, R.N., Borum, J., Roberts, R., Rysgaard, S., 2001. Photosynthetic performance of surface-associated algae below sea ice as measured with a 
pulse-amplified-modulated (PAM) fluorometer and $\mathrm{O} 2$ microsensors. Mar. Ecol. Prog. Ser. 223, 1-14.

Kuntz M (2004) Plastid terminal oxidase and its biological significance. Planta 218: 896-899.

Lavaud J, van Gorkom HJ, Etienne AL (2002) Photosystem II electron transfer cycle and chlororespiration in planktonic diatoms. Photosynthesis Research 74:5159

Lavaud J (2007) Fast regulation of photosynthesis in diatoms: Mechanisms, evolution and ecophysiology. Funct. Plant Sci. Biotech. 1: 267-287.

Lavaud J, Kroth P (2006) In diatoms, the transthylakoid proton gradient regulates the photoprotective non-photochemical fluorescence quenching beyond its control on the xanthophyll cycle. Plant Cell Physiol. 47: 1010-1016.

Lavaud J, Rousseau B, Van Gorkom H, Etienne A-L (2002) Influence of the diadinoxanthin pool size on photoprotection in the marine planktonic diatom Phaeodactylum tricornutum. Plant Physiol. 129: 1398-1406.

Lavaud J, Van Gorkom H, Etienne A-L (2002b) Photosystem II electron transfer cycle and chlororespiration in planktonic diatoms. Photosynth. Res. 74: 49-57.

Lavaud J, Strzepek RF, Kroth PG (2007) Photoprotection capacity differs among diatoms: Possible consequences on the spatial distribution of diatoms related to fluctuations in the underwater light climate. Limnol. Oceanogr. In press.

Lefebvre, S., Mouget, J.L., Loret, P., Tremblin, G., 2007. Comparison between fluorimetry and oxymetry techniques to measure photosynthesis in the diatom Skeletonema costatum cultivated under simulated seasonal conditions. Journal of Photochemistry and Photobiology: B Biology 86, 131-139. 
Lomas MW, Glibert PM (1999) Temperature regulation of nitrate uptake: A novel hypothesis about nitrate uptake and reduction in cool-water diatoms. Limnol Oceanogr 44:556-572

Longstaff BJ, Kildea T, Runcie JW, Chesshire A, Dennison WC, Hurd C, Kana TM, Larkum AWD (2002) An in situ study of photosynthetic oxygen exchange and electron transport rate in the marine macroalga Ulva lactuca (Chlorophyta). Photosynthesis Research 74:281-293

Masojidek, J., Grobbelaar, J.U., Pechar, L., Koblizek, M., 2001. Photosystem II electron transport rates and oxygen production in natural waterblooms of freshwater cyanobacteria during a diel cycle. J. Plankton Res. 23, 57-66.

Mauzerall D, Greenbaum NL (1989) The Absolute Size of a Photosynthetic Unit. Biochimica et Biophysica Acta 974:119-140

McGinn PJ, Morel FMM (2008) Expression and inhibition of the carboxylating and decarboxylating enzymes in the photosynthetic C-4 pathway of marine diatoms. Plant Physiology 146:300-309

Melrose, D.C., Oviatt, C.A., O'Reilly, J.E., Berman, M.S., 2006. Comparisons of fast repetition rate fluorescence estimated primary production and C-14 uptake by phytoplankton. Marine Ecology-Progress Series 311, 37-46.

Mercado JM, Sanchez-Saavedra MD, Correa-Reyes G, Lubian L, Montero O, Figueroa FL (2004) Blue light effect on growth, light absorption characteristics and photosynthesis of five benthic diatom strains. Aquatic Botany 78:265-277

Migne, A., Gevaert, F., Creach, A., Spilmont, N., Chevalier, E., Davoult, D., 2007. Photosynthetic activity of intertidal microphytobenthic communities during 
emersion: in situ measurements of chlorophyll fluorescence (PAM) and CO2 flux (IRGA). Journal Of Phycology 43, 864-873.

Moore, C.M., Suggett, D., Holligan, P.M., Sharples, J., Abraham, E.R., Lucas, M.I., Rippeth, T.P., Fisher, N.R., Simpson, J.H., Hydes, D.J., 2003. Physical controls on phytoplankton physiology and production at a shelf sea front: a fast repetition-rate fluorometer based field study. Mar. Ecol. Prog. Ser. 259, $29-45$.

Morris, E.P., Kromkamp, J.C., 2003. Influence of temperature on the relationship between oxygen- and fluorescence-based estimates of photosynthetic parameters in a marine benthic diatom (Cylindrotheca closterium). Eur. J. Phycol. 38, 133-142.

Morris EP, Forster RM, Peene J, Kromkamp JC (2008) Coupling between Photosystem II electron transport and carbon fixation in microphytobenthos. Aquatic Microbial Ecology 50:301-311

Morris EP, Kromkamp JC (2003) Influence of temperature on the relationship between oxygen- and fluorescence-based estimates of photosynthetic parameters in a marine benthic diatom (Cylindrotheca closterium). European Journal of Phycology 38:133-142

Mouget J.-L, Tremblin G (2002). Suitability of the Fluorescence Monitoring System (FMS, Hansatech) for measurement of photosynthetic characteristics in algae. Aquat. Bot. 74: 219-231.

Myers J, Graham JR (1971) Photosynthetic Unit in Chlorella Measured by Repetitive Short Flashes. Plant Physiology 48:282-and 
Nelson NB, Prezelin BB, Bidigare RR (1993) Phytoplankton Light-Absorption and the Package Effect in California Coastal Waters. Marine Ecology-Progress Series 94:217-227

Perkins RG, Underwood GJC, Brotas V, Snow GC, Jesus B, Ribeiro L (2001) Responses of microphytobenthos to light: primary production and carbohydrate allocation over an emersion period. Mar. Ecol. Prog. Ser. 223: 101-112.

Perkins RG, Oxborough K, Hanlon ARM, Underwood GJC, Baker NR (2002) Can chlorophyll fluorescence be used to estimate the rate of photosynthetic electron transport within microphytobenthic biofilms? Mar. Ecol. Prog. Ser. 228: $47-56$.

Perkins RG, Mouget J-L, Lefebvre S., Lavaud J (2006) Light response curve methodology and possible implications in the application of chlorophyll fluorescence to benthic diatoms. Mar. Biol. 149: 703-712.

Perkins RG, Kromkamp J, Reid RP (2007) How do stromatolite photosynthetic communities tolerate natural sand burial events? The roles of light and oxygen in photochemical reactivation. Mar. Ecol. Prog Ser. 349: 23-32, 2007

Prasil, O., Kolber, Z., Berry, J.A., Falkowski, P.G., 1996. Cyclic electron flow around photosystem II in vivo. Photosynthesis Research 48, 395-410.

Raateoja M, Seppala J, Kuosa H (2004) Bio-optical modelling of primary production in the SW Finnish coastal zone, Baltic Sea: fast repetition rate fluorometry in Case 2 waters. Marine Ecology-Progress Series 267:9-26

Raateoja, M.P., 2004. Fast repetition rate fluorometry (FRRF) measuring phytoplankton productivity: A case study at the entrance to the Gulf of Finland, Baltic Sea. Boreal Environment Research 9, 263-276. 
Raateoja, M.P., Seppala, J., 2001. Light utilization and photosynthetic efficiency of Nannochloris sp (Chlorophyceae) approached by spectral absorption characteristics and Fast Repetition Rate Fluorometry (FRRF). Boreal Environment Research 6, 205-220.

Rech M, Mouget J-L, Morant-Manceau A, Rosa P, Tremblin G (2005) Long-term acclimation to UV radiation: effects on growth, photosynthesis and carbonic anhydrase activity in marine diatoms. Bot. Mar. 48: 407-420.

Rech, M, 2004. Effets de l'éclairement visible et ultraviolet sur la croissance et la photosynthèse de microalgues: incidences sur l'écophysiologie du phytoplancton des claires ostréicoles. PhD Thesis, Le Mans University, 200 p

Rees, D., Lee, C.B., Gilmour, D.J., Horton, P., 1992. Mechanisms For Controlling Balance Between Light Input And Utilization In The Salt Tolerant Alga Dunaliella C9aa. Photosynthesis Research 32, 181-191.

Revsbech NP, Jørgensen BB (1983) Photosynthesis of benthic microflora measured with high spatial resolution by the oxygen microprofile method: capabilities and limitations of the method. Limnology and Oceanography 28:749-756

Ruban VA, Lavaud J, Rousseau B, Guglielmi G, Horton P, Etienne A-L (2004) The super-excess energy dissipation in diatom algae: comparative analysis with higher plants. Photosynth. Res. 82: 165-175.

Rysgaard, S., Kuhl, M., Glud, R.N., Hansen, J.W., 2001. Biomass, production and horizontal patchiness of sea ice algae in a high-Arctic fjord (Young Sound, NE Greenland). Marine Ecology-Progress Series 223, 15-26.

Sagert, S., Schubert, H., 2000. Acclimation of Palmaria palmata (Rhodophyta) to light intensity: Comparison between artificial and natural light fields. Journal Of Phycology 36, 1119-1128. 
Sarma, V.V.S.S., Abe, O., Hashimoto, S., Hinuma, A., Saino, T., 2005. Seasonal variations in triple oxygen isotopes and gross oxygen production in the Sagami Bay, central Japan. Limnol. Oceanogr. 50, 544-552.

Sarma, V.V.S.S., Abe, O., S., Hinuma, A., Saino, T., 2006. Short-term variation of triple oxygen isotopes and gross oxygen production in the Sagami Bay, central Japan. Limnol. Oceanogr. 51, 1432-1442.

Schofield, O., Kroon, B.M.A., Prezelin, B.B., 1995. Impact Of Ultraviolet-B Radiation On Photosystem-Ii Activity And Its Relationship To The Inhibition Of Carbon Fixation Rates For Antarctic Ice Algae Communities. Journal Of Phycology 31, 703-715.

Schreiber U, Schliwa U, Bilger W (1986) Continuous recording of photochemical and non-photochemical chlorophyll fluorescence quenching with a new type of modulation fluorometer. Photosynthesis Research 10:51-62

Schreiber U, Hormann H, Neubauer C, Klughammer C (1995) Assessment of photosystem II photochemical quantum yield by chlorophyll fluorescence quenching analysis. Australian Journal of Plant Physiology 22:209-220

Schumann A, Goss R, Torsten J, Wilhelm C (2007) Investigation of the quenching efficiency of diatoxanthin in cells of Phaeodactylum tricornutum (Bacillariophyceae) with different pool sizes of xanthophyll cycle pigments. Phycologia 46: 113-117.

Serôdio J (2003) A chlorophyll fluorescence index to estimate short-term rates of photosynthesis by intertidal microphytobenthos. Journal of Phycology 39:3346 
Serôdio J, Marques da Silva J, Catarino F (1997) Non destructive tracing of migratory rhythms of intertidal benthic microalgae using in vivo chlorophyll a fluorescence. J Phycol 33: 542-553

Serôdio J, Vieira S, Barroso F (2007) Relationship of variable chlorophyll fluorescence indices to photosynthetic rates in microphytobenthos. Aquat Microb Ecol 49:71-85

Serôdio J, Cruz S, Vieira S, Brotas V (2005) Non-photochemical quenching of chlorophyll fluorescence and operation of the xanthophyll cycle in estuarine microphytobenthos. J. Exp. Mar. Biol. Ecol. 326: 157-169.

Serôdio J, Vieira S, Cruz (2005) Photosynthetic activity, photoprotection and photoinhibition in intertidal microphytobenthos as studied in situ using variable chlorophyll fluorescence. Cont. Shelf Res. 28:1363-1375

Serôdio J, Vieira S, Cruz S, Coelho H (2006) Rapid light-response curves of chlorophyll fluorescence in microalgae: relationship to steady-state light curves and non-photochemical quenching in benthic diatom-dominated assemblages. Photosynth. Res. 90: 29-43.

Serodio, J., da Silva, J.M., Catarino, F., 1998. Relationship between chlorophyll fluorescence quenching and O-2 evolution in microalgae. Photosynthesis: Mechanisms And Effects, Vols I-V, 4109-4112.

Silva, J., Santos, R., Serodio, J., Melo, R.A., 1998. Light response curves for Gelidium sesquipedale from different depths, determined by two methods: $\mathrm{O} 2$ evolution and chlorophyll fluorescence. J. Appl. Phycol. 10, 295-301.

Simis SGH, Tijdens M, Hoogveld HL, Gons HJ (2005) Optical changes associated with cyanobacterial bloom termination by viral lysis. Journal of Plankton Research 27:937-949 
Smyth, T.J., Pemberton, K.L., Aiken, J., Geider, R.J., 2004. A methodology to determine primary production and phytoplankton photosynthetic parameters from Fast Repetition Rate Fluorometry. Journal Of Plankton Research 26, $1337-1350$.

Suggett D, Kraay G, Holligan P, Davey M, Aiken J, Geider R (2001) Assessment of photosynthesis in a spring cyanobacterial bloom by use of a fast repetition rate fluorometer. Limnol Oceanogr 46:802-810

Suggett DJ, Le Floc'H E, Harris GN, Leonardos N, Geider RJ (2007) Different strategies of photoacclimation by two strains of Emiliania huxleyi (Haptophyta). Journal of Phycology 43:1209-1222

Suggett DJ, MacIntyre HL, Geider RJ (2004) Evaluation of biophysical and optical determinations of light absorption by photosystem II in phytoplankton. Limnology and Oceanography-Methods 2:316-332

Suggett DJ, Oxborough K, Baker NR, MacIntyre HL, Kana TD, Geider RJ (2003) Fast repetition rate and pulse amplitude modulation chlorophyll a fluorescence measurements for assessment of photosynthetic electron transport in marine phytoplankton. Eur J Phycol 38:371-384

Tassan S, Ferrari GM (1998) Measurement of light absorption by aquatic particles retained on filters: determination of the optical path length amplification by the 'transmittance-reflectance' method. Journal of Plankton Research 29:16991709

Ting CS, Owens TG (1993) Photochemical and non-photochemical fluorescence quenching processes in the diatom Phaeodactylum tricornutum. Plant Physiol. 101: $1323-1330$. 
Tuji A (2000) The effect of irradiance on the growth of different forms of freshwater diatoms: implications for succession in attached diatom communities. J. Phycol. 36: 659-661.

Underwood, GJC, Perkins RG, Consalvey MC, Hanlon A, Oxborough K, Baker N Paterson DM (2005) Patterns in microphytobenthic primary productivity: Species-specific variation in migratory rhythms and photosynthetic efficiency in mixed-species biofilms. Limnol. Oceanogr. 50: 755-767.

Van De Poll, W. H., M. A. Van Leeuwe, J. Roggeveld, and A. G. J. Buma. 2006. Nutrient limitation and high irradiance acclimation reduce PAR and UVinduced viability loss in the Antarctic diatom Chaetoceros brevis (Bacillariophyceae). J. Phycol. 41: 840-850.

Waring J, Underwood GJC, Baker NR (2006) Impact of elevated UV-B radiation on photosynthetic electron transport, primary productivity and carbon allocation in estuarine epipelic diatoms. Plant Cell Envir. 29: 521-534.

Williams PJL, Robertson JE (1991) Overall planktonic oxygen and carbon dioxide metabolisms: the problem of reconciling observations and calculations of photosynthetic quotients. Journal of Plankton Research 13:153-169

Williams PJB (1993) Chemical and tracer methods of measuring plankton production. In Li WKW, Maestrini SY (eds.) Measurement of primary production from the molecular to the global scale. ICES, La Rochelle, pp 21-36 
Table 1.

\begin{tabular}{|l|l|l|l|}
\hline Species & Growth conditions & $\mathrm{n}_{\text {PSII }}$ & Source \\
\hline Thalassiosira & LL & 723 & (Dubinsky et al., 1986) \\
weisflogii & HL & 552 & \\
\hline Isochrysis galbana & LL & 636 & (Dubinsky et al., 1986) \\
& HL & 264 & \\
\hline Prorocentrum & HL & 725 & (Dubinsky et al., 1986) \\
micans & LL & 513 & \\
\hline Dunaliella & LL & 710 & (Falkowski et al., 1981) \\
tertiolecta & HL & 833 & \\
\hline Skeletonema & HL & 590 & (Falkowski et al., 1981) \\
costatum & LL & 605 & \\
\hline Skeletonema & LL-sinusoidal & 467 & (Kromkamp and Limbeek, \\
costatum & ML-sinusoidal & 376 & 1993) \\
\hline Skeletonema & LL-fluctuating & 290 & (Kromkamp and Limbeek, \\
costatum & ML-fluctuating & 237 & 1993) \\
\hline Chlorella & LL & 588 & (Myers and Graham, 1971) \\
pyrenodiosa & HL & 390 & \\
\hline Emiliania huxleyi & LL & 665 & (Suggett et al., 2007) \\
B11 & HL & 488 & \\
\hline Emiliania huxleyi & LL & 720 & (Suggett et al., 2007) \\
B92 & HL & 528 & \\
\hline
\end{tabular}

${ }^{1} \mathrm{LL}=$ low light, $\mathrm{ML}=$ medium light and $\mathrm{HL}=$ high light growth conditions 
Table 2 Comparison of photosynthetic parameters in aquatic organisms obtained with fluorescence-based methods and with carbon- and oxygenbased methods

\begin{tabular}{|c|c|c|c|c|c|c|c|}
\hline Authors (year) & Methods & & Organisms & $\begin{array}{l}\text { Growth } \\
\text { irradiance / } \\
\text { photoacclimation } \\
\end{array}$ & $\begin{array}{l}\text { Observed } \\
\text { relationship }\end{array}$ & Hypothesis for NL & Remarks \\
\hline & Fluorescence & $\mathrm{O}_{2} /{ }^{14} \mathrm{C}$ & & & $\begin{array}{l}\text { Linear*/Non } \\
\text { Linear, Low-, } \\
\text { Medium-, High- } \\
\text { Irradiance } \\
\end{array}$ & & \\
\hline Babin et al (1996) & FRRF & ${ }^{14} \mathrm{C}$ & $\begin{array}{l}\text { Phytoplankton } \\
\text { Natural samples }\end{array}$ & $\begin{array}{l}\text { Ambient } \\
\text { conditions }\end{array}$ & $\mathrm{NL}$ & Nutrient limitations & \\
\hline $\begin{array}{l}\text { Barranguet and } \\
\text { Kromkamp (2000) }\end{array}$ & PAM-101 & ${ }^{14} \mathrm{C}$ & $\begin{array}{l}\text { MPB } \\
\text { Natural samples }\end{array}$ & $\begin{array}{l}\text { Ambient } \\
\text { conditions }\end{array}$ & $\begin{array}{l}\text { Mostly L, } \\
\text { sometimes } \\
\text { deviations at HI } \\
\text { No significant } \\
\text { correlation for } \\
\mathrm{P}_{\mathrm{m}}, \mathrm{E}_{\mathrm{k}} \text { or } \square \\
\text { between PAM } \\
\text { and }{ }^{14} \mathrm{C} \text { data }\end{array}$ & $\begin{array}{l}\text { Migration, change in } a^{*} \\
\text { and light absorption by } \\
\text { sediment }\end{array}$ & $\begin{array}{l}\text { Measurements in } \\
\text { parallel }\end{array}$ \\
\hline Beer et al. (1998) & $\begin{array}{l}\text { Diving-PAM } \\
\text { (LC, RLC) }\end{array}$ & $\mathrm{O}_{2}$ & $\begin{array}{l}\text { Seagrasses (Zostera marina, } \\
\text { Cymodocea nodosa, Halophila } \\
\text { stipulacea) }\end{array}$ & $\begin{array}{l}\text { Ambient } \\
\text { conditions }\end{array}$ & $\begin{array}{l}\mathrm{L}(+,=,-) \text { or } \\
\mathrm{NL}(\text { deviation at } \\
\mathrm{HI}) \text {, depending } \\
\text { on the species }\end{array}$ & $\begin{array}{l}\text { Photorespiration and other } \\
\mathrm{O}_{2} \text { consuming reactions }\end{array}$ & $\begin{array}{l}\text { Simultaneous } \\
\text { measurements (LC) }\end{array}$ \\
\hline Beer and Björk (2000) & Diving-PAM & $\mathrm{O}_{2}$ & $\begin{array}{l}\text { Seagrasses (Halophila ovalis, } \\
\text { Halodule wrightii) Natural } \\
\text { samples }\end{array}$ & $\begin{array}{l}\text { Ambient } \\
\text { conditions }\end{array}$ & $\begin{array}{l}\mathrm{L}(+,=) \text { or } \mathrm{NL} \\
\text { (deviation at } \mathrm{HI}) \text {, } \\
\text { depending on the } \\
\text { species }\end{array}$ & $\begin{array}{l}\text { Photorespiration, } \\
\text { estimation of light } \\
\text { absorbed by PSII }\end{array}$ & $\begin{array}{l}\text { Simultaneous } \\
\text { measurements }\end{array}$ \\
\hline Beer et al. (2000) & $\begin{array}{l}\text { Diving-PAM, } \\
\text { PAM-101 }\end{array}$ & $\mathrm{O}_{2}$ & $\begin{array}{l}\text { Macroalgae (Ulva lactuca, } U \text {. } \\
\text { fasciata) } \\
\text { Natural samples }\end{array}$ & 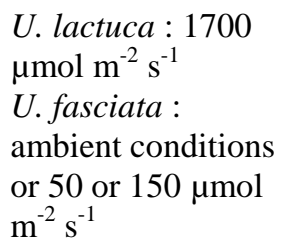 & $\mathrm{L}(=)$ & & $\begin{array}{l}\text { Simultaneous } \\
\text { measurements }\end{array}$ \\
\hline Beer and Axelsson & PAM-101, & $\mathrm{O}_{2}$ & Macroalgae (Ulva lactuca, & Acclimation to 400 & Mostly L & $\square_{\text {PSII }}$ lower than 0.1 & Simultaneous \\
\hline
\end{tabular}


(2004)

Diving-PAM

Boyd et al (1997)

Cabello-Pasini and

Figueroa (2005)

Carr and Björk (2003)

Diving-PAM,

PAM-2000

(LC, RLC)

Carr and Björk (2007)

PAM-2000

$\mathrm{O}_{2} \quad$ Ulva fasciata

Corno et al (2005)

Estevez-Blanco et al

(2006)

Falkowski et al (1986a)

PPF
Fucus serratus, Laminaria saccharina, Palmaria palmata

\section{${ }^{14} \mathrm{C} \quad$ Phytoplankton assemblages \\ (field), dominance of} coccolithophorids

\section{$\mathrm{O}_{2} \quad$ Ulva rigida}

$\mathrm{O}_{2} \quad$ Ulva reticulata, $U$. fasciata

Different DIC

irradiances and

temperatures

$50 \mu \mathrm{mol} \mathrm{m} \mathrm{s}^{-2}$

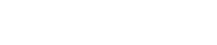

L. saccharina.

U. lactuca : 200

Ambient Porphyra umbilicalis)

$\mathrm{NL}$ at $\mathrm{HI}$

100, $400 \mu \mathrm{mol} \mathrm{m}$

$1700 \mu \mathrm{mol} \mathrm{m} \mathrm{m}^{-2}$

NL for

$L$ for $E_{k}$

Partially L (-) fo

$\mathrm{P}_{\mathrm{m}}$

parameters (esp. bio-

Mostly L (=)

NL, especially at Light history, changes in

HI or high DIC $\quad \square$ PSI

L with fresh

sample at each

light step

$\mathrm{P}_{\mathrm{mf}} / \mathrm{P}_{\mathrm{m}}$ changing

with I

$80 \mu \mathrm{mol} \mathrm{m} \mathrm{m}^{-2} \quad$ Stable ratio (=)

Nutrient limitation $\quad \mathrm{P}_{\mathrm{mf}} / \mathrm{P}_{\mathrm{m}}$

Ambient irradiance L (+)

Divergence in
primary
production
estimates

estimates

Ambient irradiance $\mathrm{L}(+)$

$\left(\right.$ FAST $^{\text {tracka }}$
${ }^{14} \mathrm{C} \quad$ Phytoplankton assemblages (field)
$\mathrm{O}_{2} \quad$ Thalasiossira weissflogii,

$\mathrm{L}$ at $\mathrm{MI}$, itations in the

determination of some

optical), differences in

light sources and

measurement duration

Lower correlation at $\mathrm{HI}$

and high nitrate

concentration

Significant

correlations

observed, but

parameter values

differed

Simultaneous

measurements

Simultaneous

measurements

Simultaneous

measurements at one saturating non-

inhibitory irradiance level

$\mathrm{O}_{2}$ consumption processes

(mitochondrial,

photorespiration, Mehler

reaction), species

composition, vertical

distribution

Quenching phenomenon 


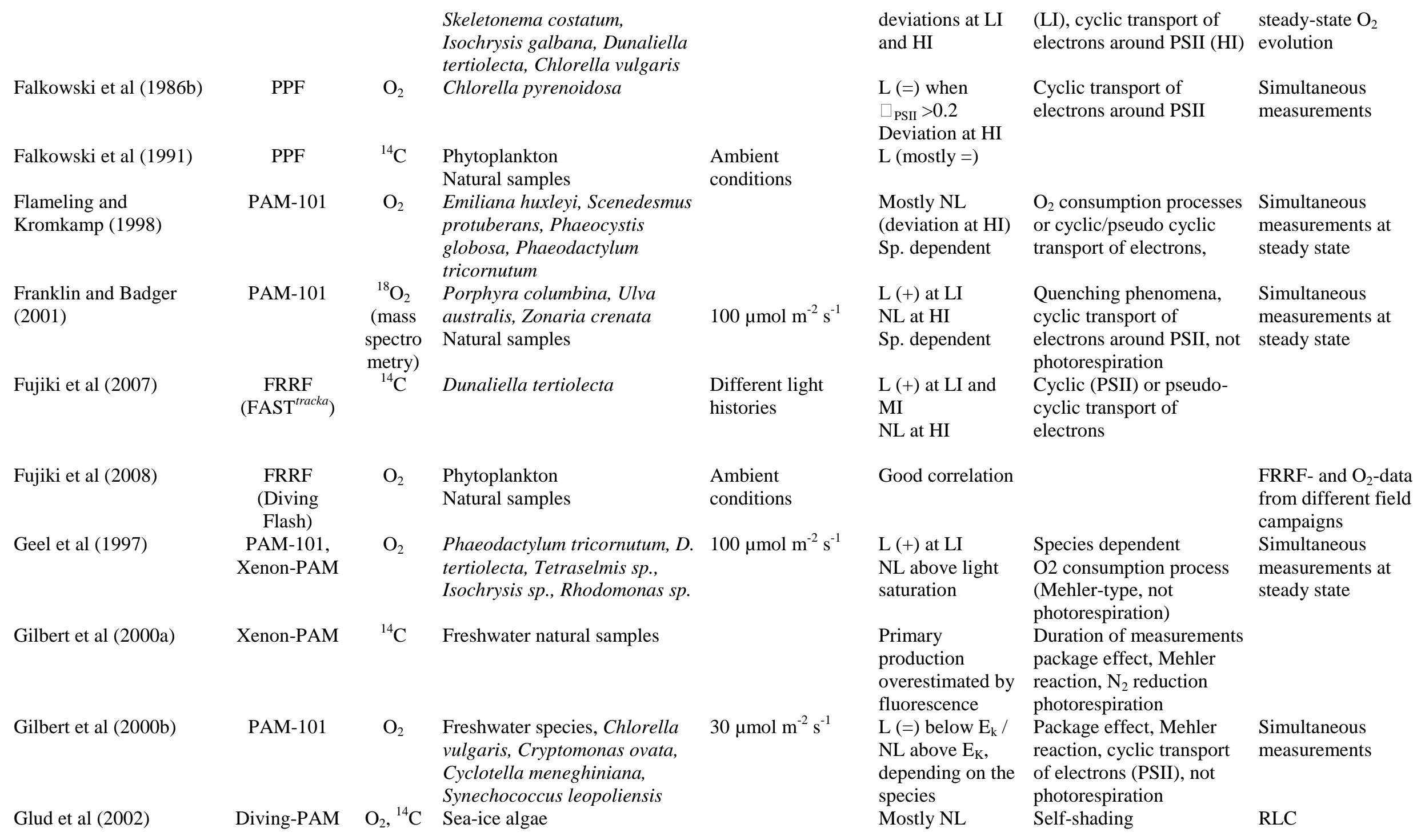




\begin{tabular}{|c|c|c|c|c|c|c|c|}
\hline Häder et al (1997) & PAM-2000 & $\mathrm{O}_{2}$ & $\begin{array}{l}\text { Cladophora prolifera, } C \text {. } \\
\text { pellucida } \\
\text { Natural samples }\end{array}$ & $\begin{array}{l}\text { Ambient } \\
\text { conditions }\end{array}$ & Good correlation & & $\begin{array}{l}\text { Follow-up of diel } \\
\text { photoinhibition and } \\
\text { recovery }\end{array}$ \\
\hline Hancke et al (2008a) & PAM-101 & $\mathrm{O}_{2},{ }^{14} \mathrm{C}$ & $\begin{array}{l}\text { Prorocentrum minimum, } \\
\text { Prymnesium parvum, } \\
\text { Phaeodactylum tricornutum }\end{array}$ & $\begin{array}{l}\text { Continuous light } \\
80 \mu \mathrm{mol} \mathrm{m} \mathrm{m}^{-2} \mathrm{~s}^{-1}\end{array}$ & $\begin{array}{l}\text { Mostly } \mathrm{L}(+,=) \\
\square, \mathrm{E}_{\mathrm{k}} \text {, to a lesser } \\
\text { extent } \mathrm{P}_{\mathrm{m}}\end{array}$ & $\begin{array}{l}\text { Species-specific } \\
\text { differences (especially for } \\
\mathrm{P}_{\mathrm{m}} \text { ) } \\
\text { Mehler reaction }\end{array}$ & $\begin{array}{l}\text { Measurements in } \\
\text { parallel } \\
\text { Fluorescence at } \\
\text { steady state }\end{array}$ \\
\hline Hancke et al (2008b) & PAM-101 & $\mathrm{O}_{2}$ & $\begin{array}{l}\text { Prorocentrum minimum, } \\
\text { Prymnesium parvum, } \\
\text { Phaeodactylum tricornutum }\end{array}$ & $\begin{array}{l}\text { Continuous light } \\
80 \mu \mathrm{mol} \mathrm{m}^{-2} \mathrm{~s}^{-1}\end{array}$ & $\begin{array}{l}\mathrm{L}(-,=,+), \\
\text { depending on the } \\
\text { method } \\
\text { High correlation } \\
\text { for } \mathrm{P}_{\mathrm{m}} \text {, weak for } \\
\square \text { and } \mathrm{E}\end{array}$ & $\begin{array}{l}\text { Differences in slope } \\
\text { coefficient in function of } \\
\text { the estimation of light } \\
\text { absorbed by PSII }\end{array}$ & $\begin{array}{l}\text { Simultaneous } \\
\text { measurements at } \\
\text { steady state } \\
\text { Different approaches } \\
\text { to estimate quanta } \\
\text { absorbed by PSII }\end{array}$ \\
\hline $\begin{array}{l}\text { Hanelt and Nultsch } \\
\text { (1995) }\end{array}$ & PAM-2000 & $\mathrm{O}_{2}$ & $\begin{array}{l}\text { Palmaria palmata } \\
\text { Natural samples }\end{array}$ & & NL & $\begin{array}{l}\text { Differences in the role of } \\
\text { pigments }\end{array}$ & $\begin{array}{l}\text { Simultaneous } \\
\text { measurements }\end{array}$ \\
\hline Hanelt et al (1995) & PAM-101 & $\mathrm{O}_{2}$ & $\begin{array}{l}\text { Dictyota dichotoma } \\
\text { Natural samples }\end{array}$ & & $\mathrm{L}$ & & $\begin{array}{l}\text { Simultaneous } \\
\text { measurements }\end{array}$ \\
\hline Heinze et al (1996) & PAM-101 & $\mathrm{O}_{2}$ & $\begin{array}{l}\text { Scenedesmus obliquus } \\
\text { Freshwater species }\end{array}$ & $100 \mu \mathrm{mol} \mathrm{m} \mathrm{m}^{-2} \mathrm{~s}^{-1}$ & $\mathrm{~L}(=)$ & & $\begin{array}{l}\text { problematical } \\
\text { Simultaneous } \\
\text { measurements at } \\
\text { steady state }\end{array}$ \\
\hline $\begin{array}{l}\text { Kaiblinger and Dokulil } \\
\text { (2006) }\end{array}$ & $\begin{array}{c}\text { FRRF } \\
\left(\text { FAST }^{\text {tracka }}\right)\end{array}$ & ${ }^{14} \mathrm{C}$ & $\begin{array}{l}\text { Freshwater phytoplankton } \\
\text { Dominant organisms : } \\
\text { Planktothrix rubescens } \\
\text { (summer) or diatoms }\end{array}$ & & $\begin{array}{l}\mathrm{L}(=) \text { at } \\
\text { subsaturating I }\end{array}$ & $\begin{array}{l}\text { Influence of high surface } \\
\text { irradiance }\end{array}$ & Vertical profiles \\
\hline Koblizek et al (1999) & $\begin{array}{l}\text { PAM-101, } \\
\text { PEA, PSI }\end{array}$ & $\mathrm{O}_{2}$ & $\begin{array}{l}\text { Spongiochloris } s p \\
\text { Freshwater species. }\end{array}$ & $20 \mu \mathrm{mol} \mathrm{m} \mathrm{s}^{-2} \mathrm{~s}^{-1}$ & Mostly L (=) & & $\begin{array}{l}\text { Exposure for } 120 \\
\min \text { to } 1000 \mu \mathrm{mol} \mathrm{m}\end{array}$ \\
\hline
\end{tabular}




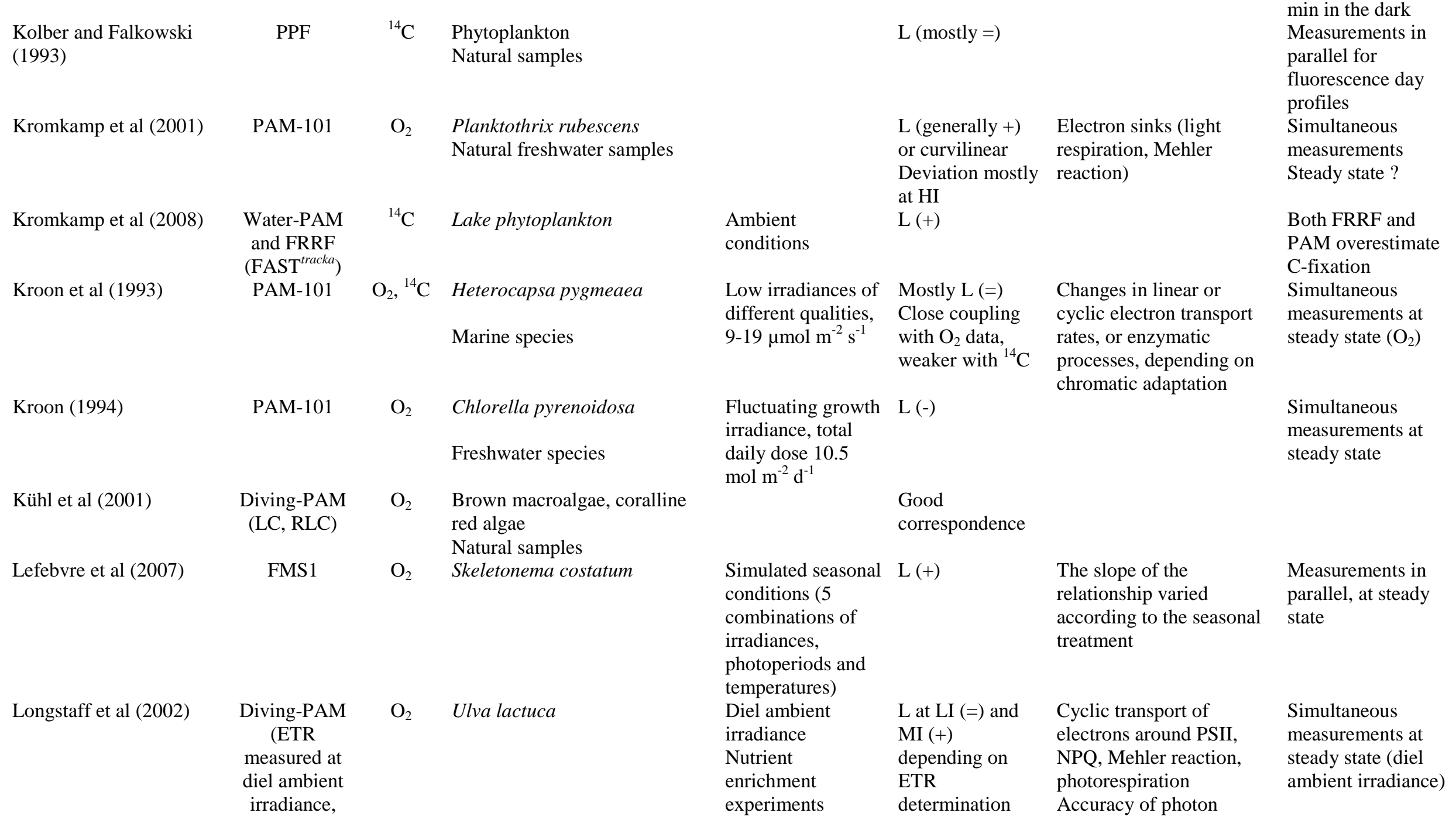


and by RLC)

\begin{tabular}{|c|c|c|c|}
\hline Masojidek et al (2001) & PAM-101 & $\mathrm{O}_{2}$ & $\begin{array}{l}\text { Freshwater cyanobacteria } \\
\text { Natural samples }\end{array}$ \\
\hline Melrose et al (2006) & $\begin{array}{c}\text { FRRF } \\
\left(\text { FAST }^{\text {tracka }}\right)\end{array}$ & ${ }^{14} \mathrm{C}$ & Coastal phytoplankton \\
\hline Migné et al (2007) & Diving-PAM & $\begin{array}{c}\mathrm{CO}_{2} \\
(\mathrm{IRGA})\end{array}$ & $\begin{array}{l}\text { MPB } \\
\text { Natural assemblages }\end{array}$ \\
\hline Moore et al (2003) & $\begin{array}{c}\text { FRRF } \\
\left(\text { FAST }^{\text {tracka }}\right)\end{array}$ & ${ }^{14} \mathrm{C}$ & $\begin{array}{l}\text { Phytoplankton } \\
\text { Natural assemblages }\end{array}$ \\
\hline $\begin{array}{l}\text { Morris and Kromkamp } \\
\text { (2003) }\end{array}$ & PAM-101 & $\mathrm{O}_{2}$ & Cylindrotheca closterium \\
\hline Morris et al (2008) & $\begin{array}{l}\text { MiniPAM, } \\
\text { Water-PAM }\end{array}$ & ${ }^{14} \mathrm{C}$ & $\begin{array}{l}\text { MPB in tidal mesocosms } \\
\text { Measurements made on } \\
\text { biofilms (ETR) and } \\
\text { suspensions (ETR, }{ }^{14} \mathrm{C} \text { ) }\end{array}$ \\
\hline Perkins et al (2001) & Diving-PAM & ${ }^{14} \mathrm{C}$ & $\begin{array}{l}\text { MPB } \\
\text { Natural assemblages }\end{array}$ \\
\hline Perkins et al (2002) & $\begin{array}{l}\text { Xenon-PAM, } \\
\text { High } \\
\text { resolution } \\
\text { imaging }\end{array}$ & ${ }^{14} \mathrm{C}$ & $\begin{array}{l}\text { MPB } \\
\text { Natural assemblages }\end{array}$ \\
\hline
\end{tabular}

NL at HI absorbance by thalli

Diel ambient light Mostly L (+) at Photorespiration, Mehler $\mathrm{LI}$ and NL at HI reaction

Diel changes

Ambient L (-)

conditions

L (-)

Diel ambient light, Mostly L

screened by the NL at HI,

Perspex dome for depending on

benthic chambers season and

station

Ambient light

regimes

and FRRF-

modelled

productivity

estimates

NL $(\square)$

Two growth rates, Mostly L

7 temperatures NL at LI and HI

(short-term

change)

$200 \mu \mathrm{mol} \mathrm{m} \mathrm{m}^{-2} \mathrm{~s}^{-1}$

Good correlation

(=) ETR/P $/ \mathrm{P}_{\mathrm{m}}$ for

suspensions,

weaker for

biofilms

Ambient irradiance L at LI, MI

(100 and 50\%) NL at HI

Ambient irradiance NL

$220 \mu \mathrm{mol} \mathrm{m} \mathrm{s}^{-2}$

(Imaging system)
Simultaneous

measurements

possibly at steady

state

FRRF mainly

underestimated $\mathrm{C}$ -

fixation

Migration, relative Measurements in

contribution of

surface/subsurface cells

parallel on different

samples

$\mathrm{O}_{2}$ consumption processes Spectral differences or non linear transports of between light source

electrons (underwater light

field in situ,

incubators)

Alternative electron sinks

(HI), variation in

respiration rates $(\mathrm{LI})$

$\mathrm{ETR} / \mathrm{O}_{2}$ relationship hardly influenced by

temperature

Measurements in

parallel

phase, diel rhythm,

migration, absorption

cross-section of MPB,

Vertical migration and

relative contribution of

surface/subsurface cells

PSI contribution, vertical

migration, relative

contribution of

surface/subsurface cells
Measurements in parallel in sample cores

Measurements in parallel on sample cores 
system

\begin{tabular}{|c|c|c|c|c|c|c|c|}
\hline Prasil et al (1996) & FRRF & $\mathrm{O}_{2}$ & $\begin{array}{l}\text { Chlorella pyrenoidosa } \\
\text { Freshwater species }\end{array}$ & $50 \mu \mathrm{mol} \mathrm{m} \mathrm{s}^{-1}$ & NL at $\mathrm{HI}$ & & $\begin{array}{l}\text { Redox state of PQ, } \\
\text { cyclic transport } \\
\text { around PSII }\end{array}$ \\
\hline $\begin{array}{l}\text { Raateoja and Seppälä } \\
\text { (2001) }\end{array}$ & $\begin{array}{c}\text { FRRF } \\
\left(\text { FAST }^{\text {tracka }}\right)\end{array}$ & ${ }^{14} \mathrm{C}, \mathrm{O}_{2}$ & $\begin{array}{l}\text { Nannochloris } s p . \\
\text { Marine species }\end{array}$ & $\begin{array}{l}39 \text { and } 314 \mu \mathrm{mol} \\
\mathrm{m}^{-2} \mathrm{~s}^{-1}\end{array}$ & NL & $\begin{array}{l}\text { Pre-set parameters to } \\
\text { convert electron flows } \\
\text { into primary productivity, } \\
\text { nitrogen reduction }\end{array}$ & $\begin{array}{l}\text { Influence of growth } \\
\text { irradiance, diel cycle } \\
\text { and nutrient uptake }\end{array}$ \\
\hline Raateoja (2004) & $\begin{array}{c}\text { FRRF } \\
\left(\text { FAST }^{\text {tracka }}\right)\end{array}$ & ${ }^{14} \mathrm{C}$ & $\begin{array}{l}\text { Phytoplankton } \\
\text { Natural assemblages }\end{array}$ & Ambient irradiance & $\begin{array}{l}\mathrm{L} \text { at } \mathrm{LI} \\
\mathrm{NL} \text { at } \mathrm{HI}\end{array}$ & $\begin{array}{l}\text { Methodological } \\
\text { discrepancy } \\
\text { (measurement periods) }\end{array}$ & $\begin{array}{l}\text { Deviation from } \\
\text { linearity at } \\
\text { irradiance } \\
>200 \mu \mathrm{mol} \mathrm{m}{ }^{-2} \mathrm{~s}^{-1}\end{array}$ \\
\hline Raateoja et al (2004) & $\begin{array}{c}\text { FRRF } \\
\left(\text { FAST }^{\text {tracka }}\right)\end{array}$ & ${ }^{14} \mathrm{C}$ & $\begin{array}{l}\text { Phytoplankton } \\
\text { Natural assemblages }\end{array}$ & $\begin{array}{l}\text { Ambient irradiance } \\
\text { (primary } \\
\text { production), } \\
\text { fluorescent tubes } \\
\text { (P/E curves) }\end{array}$ & NL & $\begin{array}{l}\text { Differences in light } \\
\text { sources, inadequacy of } \\
\text { FRRF for near-surface } \\
\text { measurements }\end{array}$ & \\
\hline \multirow[t]{2}{*}{ Rech (2004) } & FMS1 & $\mathrm{O}_{2}$ & $\begin{array}{l}\text { Amphora coffeaeformis, Haslea } \\
\text { ostrearia, Entomoneis } \\
\text { paludosa, Phaeodactylum } \\
\text { tricornutum, Porphyridium } \\
\text { cruentum, }\end{array}$ & $100 \mu \mathrm{mol} \mathrm{m} \mathrm{m}^{-2}$ & $\begin{array}{l}\mathrm{L} \text { at } \mathrm{LI} \text { and } \mathrm{MI} \\
\mathrm{NL} \text { at } \mathrm{HI}\end{array}$ & & $\begin{array}{l}\text { Species-dependent } \\
\text { relation }\end{array}$ \\
\hline & & & $\begin{array}{l}\text { Skeletonema costatum, } H \text {. } \\
\text { ostrearia, Dunaliella } \\
\text { tertiolecta, } P \text {. cruentum, } \\
\text { Spirulina platensis }\end{array}$ & $\begin{array}{l}75 \text { and } 350 \mu \mathrm{mol} \\
\mathrm{m}^{-2} \mathrm{~s}^{-1}\end{array}$ & $\begin{array}{l}\mathrm{L} \text { at } \mathrm{LI} \text { and } \mathrm{MI} \\
\mathrm{NL} \text { at } \mathrm{HI}\end{array}$ & & $\begin{array}{l}\text { Relation varying } \\
\text { with the species, and } \\
\text { the growth } \\
\text { irradiance }\end{array}$ \\
\hline Rees et al (1992) & PAM-101? & $\mathrm{O}_{2}$ & $\begin{array}{l}\text { Dunaliella sp. } \\
\text { Marine species }\end{array}$ & $40 \mu \mathrm{mol} \mathrm{m} \mathrm{s}^{-2}$ & NL & $\begin{array}{l}\text { Cyclic transport around } \\
\text { PSI and PSII, Mehler } \\
\text { reaction, etc. }\end{array}$ & \\
\hline Rysgaard et al (2001) & $\begin{array}{l}\text { Diving-PAM } \\
\text { (RLC) }\end{array}$ & $\mathrm{O}_{2},{ }^{14} \mathrm{C}$ & $\begin{array}{l}\text { Sea ice algae } \\
\text { Natural communities }\end{array}$ & Ambient irradiance & $\mathrm{L}$ & & $\begin{array}{l}\text { Calibration } \\
{ }^{14} \mathrm{C} / \mathrm{rETR} \text { (in situ } \\
\mathrm{RLCs} \text {, and parallel } \\
\text { measurements on ice }\end{array}$ \\
\hline
\end{tabular}




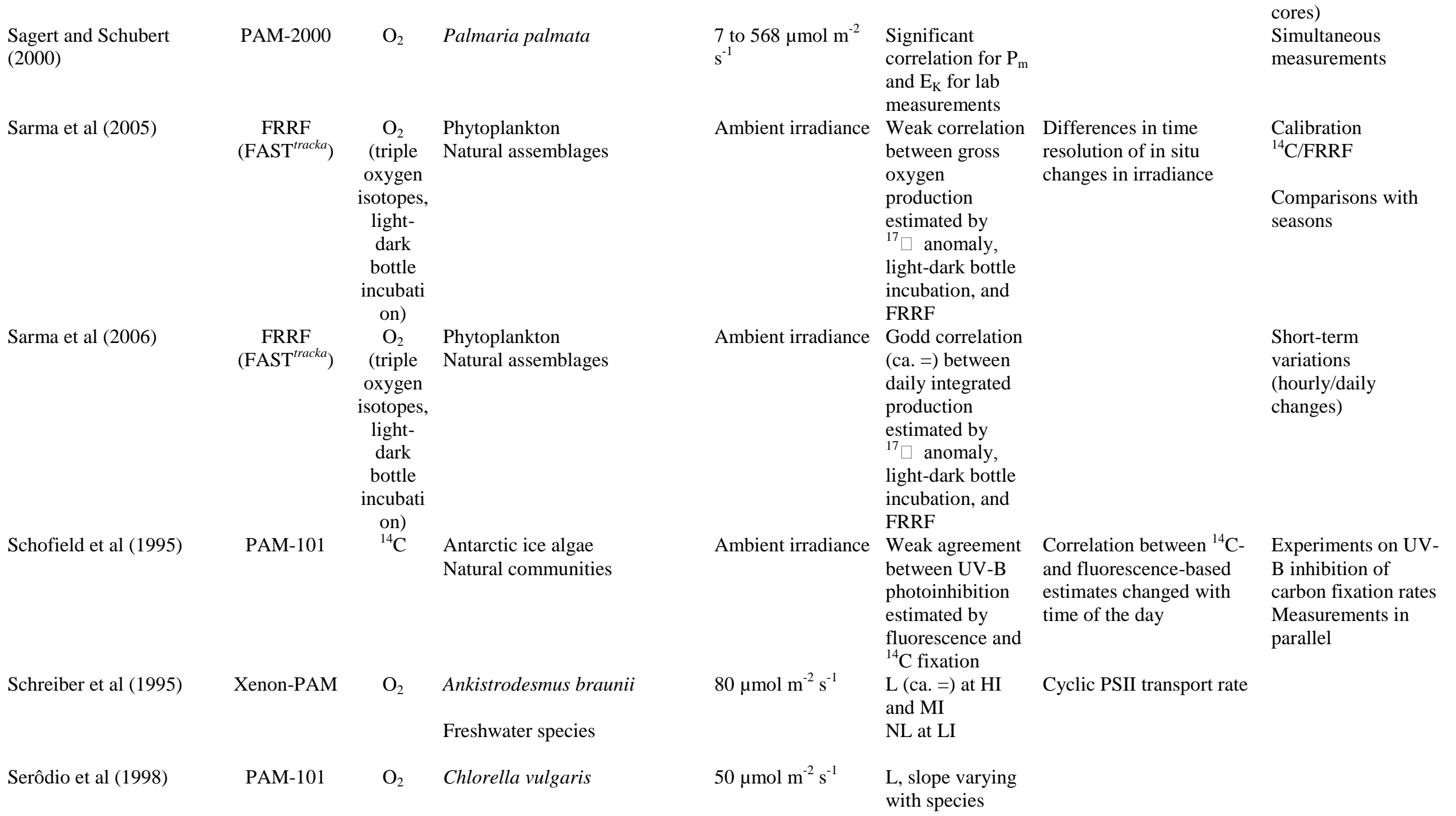




\section{Spirulina maxima}

\begin{tabular}{|c|c|c|c|}
\hline Serôdio (2003) & PAM-101 & $\mathrm{O}_{2}$ & $M P B$ \\
\hline \multirow[t]{2}{*}{ Serôdio et al (2007) } & $\begin{array}{l}\text { WATER- } \\
\text { PAM }\end{array}$ & $\mathrm{O}_{2}$ & $\begin{array}{l}\text { Natural sediment cores } \\
M P B\end{array}$ \\
\hline & & & Natural sediment cores \\
\hline Silva et al (1998) & PAM-2000 & $\mathrm{O}_{2}$ & Gelidium sesquipedale \\
\hline Smyth et al (2004) & $\begin{array}{c}\text { FRRF } \\
\text { tracka }\end{array}$ & ${ }^{14} \mathrm{C}$ & Phytoplankton assemblages \\
\hline & $\left(\mathrm{FAST}^{\text {iracka }}\right)$ & $\begin{array}{l}\text { (Daily } \\
\text { primary } \\
\text { producti } \\
\text { on, LC) }\end{array}$ & Natural communities \\
\hline Suggett et al (2001) & FRRF & ${ }^{14} \mathrm{C}, \mathrm{O}_{2}$ & $\begin{array}{l}\text { Phytoplankton assemblages } \\
\text { Natural communities }\end{array}$ \\
\hline \multirow[t]{3}{*}{ Suggett et al (2003) } & $\begin{array}{c}\text { Xenon-PAM, } \\
\text { FRRF } \\
\text { (Chelsea) }\end{array}$ & $\begin{array}{l}\mathrm{O}_{2} \\
\text { (flash } \\
\text { yield) }\end{array}$ & $\begin{array}{l}\text { Chaetoceros muelleri, } \\
\text { Prorocentrum minimum, } \\
\text { Dunaliella tertiolecta, } \\
\text { Emiliana huxleyi }\end{array}$ \\
\hline & & & Prochlorococcus marinus \\
\hline & $\begin{array}{l}\text { FRRF } \\
\text { (Chelsea) }\end{array}$ & $\begin{array}{l}{ }^{18} \mathrm{O}_{2} \\
\text { (mass } \\
\text { spectro } \\
\text { metry) }\end{array}$ & $\begin{array}{l}\text { D. tertiolecta, Thalasiossira } \\
\text { weissflogii, Nannochloris } \\
\text { atomus }\end{array}$ \\
\hline
\end{tabular}

Ambient irradiance L

Ambient irradiance L

Ambient irradiance L

Ambient irradiance NL ( $\square$ usually Integration with time and higher, $\mathrm{P}_{\mathrm{m}}$ and $\mathrm{E}_{\mathrm{k}}$ depth of instantaneous

lower, when fluorescence data

FRRF-estimated)

Ambient irradiance Good correlation FRRF estimation of

( $\square, \mathrm{P}_{\mathrm{m}}$ usually photosynthetic unit size,

higher, $\mathrm{E}_{\mathrm{k}}$ lower, respiration, alternative

when FRRF- electron sinks

estimated)

50 or $75 \mu \mathrm{mol} \mathrm{m} \mathrm{m}^{-2}$

$\mathrm{s}^{-1}$ (LI)

400 or $375 \mu \mathrm{mol}$

$\mathrm{m}^{-2} \mathrm{~s}^{-1}(\mathrm{HI})$

NL (PAM

FRRF),

Differences between

$5-10 \mu \mathrm{mol} \mathrm{m} \mathrm{s}^{-2}$

$\begin{array}{ll}\text { differences being } & \text { measurements explained } \\ \text { lower at HI } & \text { by distinct approaches }\end{array}$

PAM and FRRF

(single-vs multiple turn-

(single- vs multiple turn-
over)

$\mathrm{L}(-,=)$

depending on the

species
Changes in biomass profile due to

vertical migration

Depth-integration of subsurface

fluorescence

Good correlation

whatever the depth
Simultaneous measurements 
*When the relation is linear, ETR estimated photosynthesis can be equal (=), over- $(+)$, or under-estimated in comparison with carbon- or oxygen-based method. 


\section{Figure Legends}

Fig 2.1. Figure 4 from Serodio 2004 Joao - please write new legend

Figure 2.2. Quantum efficiency of individual cells of five benthic diatom species obtained using high resolution fluorescence imaging. By this method, only cells at the surface of the sediment were analysed, reducing any effect from sub-surface cells.

Figure 2.3. Cross sectioned sample from a stromatolite showing the surface mixed community and sub-surface layer of cyanobacteria (Reproduced courtesy of P. Reid)

Figure 2.4. Surface mixed eukaryotic microalgae and cyanobacteria mat on a stromatolite, note the fluffy three dimensional structure of the mat.

Figure 2.5. Light response curves for two stromatolite samples using a fluorimeter probe in the top-down position. The first sample (closed symbols) refers to a layer of cyanobacteria measured at $4 \mathrm{~mm}$ depth in the ooids matrix, data clearly show a large decrease in rETR post scraping away of the surface ooids. The second sample (open symbols) refers to a layer $1 \mathrm{~mm}$ below the stromatolite surface, again rETR decreased significantly post scraping.

Figure 3.1. NPQ versus irradiance (PPFD, Photosynthetic Photon Flux Density ) in

different species of diatoms : in black, planktonic species from the open ocean (Thalassiosira oceanica), coastal (Skeletonema costatum) and estuarine (Phaeodactylum tricornutum) habitats, in white three benthic species isolated from the 
microphytobenthos (MPB) in Baie de Bourgneuf (Atlantic coast, France). Adapted from Lavaud et al. (2007) (planktonic species) and unpublished data (benthic species).

Figure 3.2. (A) Simplified scheme of the xanthophyll cycle (XC) regulation. Co-factor requirement for the enzymes is shown as well as the $\mathrm{pH}$ optimum. - $\Delta \mathrm{pH}$ means that the DT epoxidase is inhibited by high $\Delta \mathrm{pH}$ under high light (Goss et al., 2006). DD, diadinoxanthin; DT, diatoxanthin. Adapted from Lavaud (2007). (B) pH dependence of DD and VX de-epoxidation in isolated thylakoid membranes of the diatom Phaeodactylum tricornutum (open circles) and spinach (closed squares). Deepoxidation is calculated as $[\mathrm{DT} /(\mathrm{DD}+\mathrm{DT})]$ for the diatom and as $[(\mathrm{ZX}+0.5 \mathrm{AX}) /(\mathrm{VX}+\mathrm{AX}+\mathrm{ZX})]$ for the plant. $\mathrm{VX}$, violaxanthin; $\mathrm{AX}$, antheraxanthin; ZX, zeaxanthin. Adapted from Jakob et al. (2001).

Figure 3.3. (A) Fluorescence induction kinetics in a Navicula phyllepta low light culture $\left(25 \mu \mathrm{mol}\right.$ photons $\left.\mathrm{m}^{-2} \mathrm{~s}^{-1}\right)$ under a $370 \mu \mathrm{mol}$ photons $\mathrm{m}^{-2} \mathrm{~s}^{-1}$ actinic light; application of saturating pulses to measure $\mathrm{F}_{\mathrm{m}}$ ' are indicated by downward arrows after 10, 30, $60 \mathrm{~s}$ and when fluorescence reached 'steady-state' $(140 \mathrm{~s})$; NPQ $=\left(\mathrm{F}_{\mathrm{m}}\right.$ $\left.\mathrm{F}_{\mathrm{m}}{ }^{\prime}\right) / \mathrm{F}_{\mathrm{m}}$ '. (B) Rapid Light Response Curves (RLCs) of the same low light culture acclimated at $100 \mu \mathrm{mol}$ photons $\mathrm{m}^{-2} \mathrm{~s}^{-1}$ for $1 \mathrm{~h}$. (C) Maximum Electron Transport Rate (rETR max) parameter as extracted from the RLCs built on N. phyllepta low (100 $\mu \mathrm{mol}$ photons $\mathrm{m}^{-2} \mathrm{~s}^{-1}$ for $\left.1 \mathrm{~h}\right)$ and high $\left(400 \mu \mathrm{mol}\right.$ photons $\mathrm{m}^{-2} \mathrm{~s}^{-1}$ for $\left.1 \mathrm{~h}\right)$ light acclimated cultures. PPFD, Photosynthetic Photon Flux Density. Adapted from Perkins et al. (2006). 
Figure 3.4. Legend: Rapid Light Response Curves (RLCs) made in situ on an intact microphytobenthos (MPB) community (after 15 min dark adaptation) in the Eden estuary (Scotland). Each light step lasted $3 \mathrm{~min}$ and the PS II efficiency $\left(\Delta \mathrm{F} / \mathrm{F}_{\mathrm{m}}{ }^{\prime}\right)$ was measured at $30 \mathrm{~s}$ intervals. Despite the fact that $\mathrm{F}$ and $\mathrm{F}_{\mathrm{m}}$ ' only stabilized near the end of the $3 \mathrm{~min}$ exposure at each light step, $\Delta \mathrm{F} / \mathrm{F}_{\mathrm{m}}$ ' stabilized already in less than $30 \mathrm{sec}$ and rETR measurement was only disturbed for the highest intensities (over $800 \mu \mathrm{mol}$ photons. $\mathrm{m}^{-2} \cdot \mathrm{s}^{-1}$ ) whatever the length of the light steps (from 30 to $180 \mathrm{~s}$ ). (Kromkamp J., unpublished).

Fig. 5.1. Comparison between $\mathrm{rETR}_{\max }$ (left $\mathrm{Y}$-axis) and absolute $\mathrm{ETR}_{\max }$ (right $\mathrm{Y}$ axis, expressed per cell) for 4 different algal species: C. autotrophica, T. pseudonana, E. huxleyi and Synechococcus CCY9502. On day 7 (arrow) the cells were resuspended in phosphate-free medium and were thus starved for P (unpublished data from Kromkamp).

Figure 6.1. Selected HRFI fluorescence images (at $F^{\prime}$ ) used in the construction of light response curves Perkins et al. (2002). Image (a) was obtained near the start of the light curve, at $380 \mu \mathrm{mol} \mathrm{m} \mathrm{m}^{-1}$ PAR and image (b) at $1150 \mu \mathrm{mol} \mathrm{m} \mathrm{m}^{-2} \mathrm{~s}^{-1}$ PAR. Note the change in surface biofilm from a mixed diatom and euglenid community to just Euglena spp. in less than 8 minutes. Scale bar is $100 \mu \mathrm{m}$ long

Figure 6.2. Rapid light curves for cultures of $N$. phyllepta exposed to $1 \mathrm{~h}$ light acclimation period of low (a: $25 \mu \mathrm{mol}$ photons $\mathrm{m}^{-2} \mathrm{~s}^{-1}$ ) or high (b: $400 \mu \mathrm{mol}$ photons $\mathrm{m}^{-2} \mathrm{~s}^{-1}$ ) light. Light response curves were run with light step durations of 10, 30 and $60 \mathrm{~s}$ and with either increasing (up). Note the increase in $\mathrm{rETR}_{\max }$, lack of saturation 
or down regulation for light curves with incremental increases in light level, as opposed to curves with decreasing light levels where saturation and down regulation occurred. From Perkins et al. (2006).

Figure 6.3. Non-sequential Light Curves for cultures of $N$. phyllepta run with light step durations of $10,30,60 \mathrm{~s}$ and reaching steady state (SS). Note the increase in $\mathrm{rETR}_{\max }$ as a function of the duration of light step and the lack of saturation for steady state light curves. From Perkins et al. (2006).

Fig. 7.1. Relationship between modeled primary production (Y-axis) and a fluorescence index (X-axis, slightly modified after Serodio, 2003). For the calculations one set a single set of photosynthetic parameters was chosen and the results were due to differently shaped depth profiles and thus a corresponding different contribution of fluorescence originating from layers within the photic zone

Figure 7.2. 